\title{
State of the Art in Beta Titanium Alloys for Airframe Applications
}

\author{
JAMES D. COTTON ${ }^{10,6}$ ROBERT D. BRIGGS, ${ }^{1}$ RODNEY R. BOYER, ${ }^{2}$ \\ SESH TAMIRISAKANDALA ${ }^{3}$ PATRICK RUSSO ${ }^{3}$ \\ NIKOLAY SHCHETNIKOV, ${ }^{4}$ and JOHN C. FANNING ${ }^{5}$ \\ 1.-Boeing Research \& Technology, Seattle, WA, USA. 2.-RBTi Consulting, Issaquah, WA, USA. \\ 3.-RTI International Metals, Inc., Niles, OH, USA. 4.-VSMPO-AVISMA Corp., Verkhnyaya \\ Salda, Sverdlovsk Region, Russia. 5.-TIMET Metals Corp., Henderson, NV, USA. 6.-e-mail: \\ james.d.cotton@boeing.com
}

Beta titanium alloys were recognized as a distinct materials class in the $1950 \mathrm{~s}$, and following the introduction of Ti-13V-11Cr-3Al in the early $1960 \mathrm{~s}$, intensive research occurred for decades thereafter. By the $1980 \mathrm{~s}$, dozens of compositions had been explored and sufficient work had been accomplished to warrant the first major conference in 1983. Metallurgists of the time recognized beta alloys as highly versatile and capable of remarkable property development at much lower component weights than steels, coupled with excellent corrosion resistance. Although alloys such as Ti-15V-3Al-3Sn-3Cr, Ti-10V-2Fe-3Al and Ti-3AI-8V-6Cr-4Mo-4Zr (Beta C) were commercialized into well-known airframe systems by the $1980 \mathrm{~s}$, Ti-13V-11Cr-3Al was largely discarded following extensive employment on the SR-71 Blackbird. The 1990s saw the implementation of specialty beta alloys such as Beta $21 \mathrm{~S}$ and Alloy C, in large part for their chemical and oxidation resistance. It was also predicted that by the 1990s, cost would be the major limitation on expansion into new applications. This turned out to be true and is part of the reason for some stagnation in commercialization of new such compositions over the past two decades, despite a good understanding of the relationships among chemistry, processing, and performance and some very attractive offerings. Since then, only a single additional metastable beta alloy, Ti-5Al-5V-5Mo-3Cr-0.5Fe, has been commercialized in aerospace, although low volumes of other chemistries have found a place in the biomedical implant market. This article examines the evolution of this important class of materials and the current status in airframe applications. It speculates on challenges for expanding their use.

\section{INTRODUCTION}

In 1983, TMS held the first beta titanium alloys symposium in Atlanta, Georgia, followed by a second in 1993 in Denver, Colorado, and a third in 2005 in San Francisco, California. An inaugural conference of the French Titanium Association was held on the topic in 1994. These conferences, and related sources, produced influential reviews ${ }^{1-10}$ of beta alloys that continue to be of great utility. However, it has been some time since a general review was offered, and no follow-on symposium has been held since 2005 . The objective of the current article is to offer an update on the state of commercial beta titanium alloys. It will mainly address alloys for airframe applications. It will be made apparent that the pace of beta alloy development and commercialization has slowed for a variety of reasons; the initial focus on mechanical properties emphasized in the early years transitioned to alloy development for chemical resistance, and most recently, for easier processability and reduced cost. Early fundamental work, which revealed the complex phase equilibria, transformations, and microstructural development of beta titanium alloys, created an excellent foundation for efforts in recent decades and those to come.

\section{DEFINING CHARACTERISTICS OF BETA TITANIUM ALLOYS}

Beta titanium alloys derive their name from the high volume fraction of the body-centered cubic (bcc) 

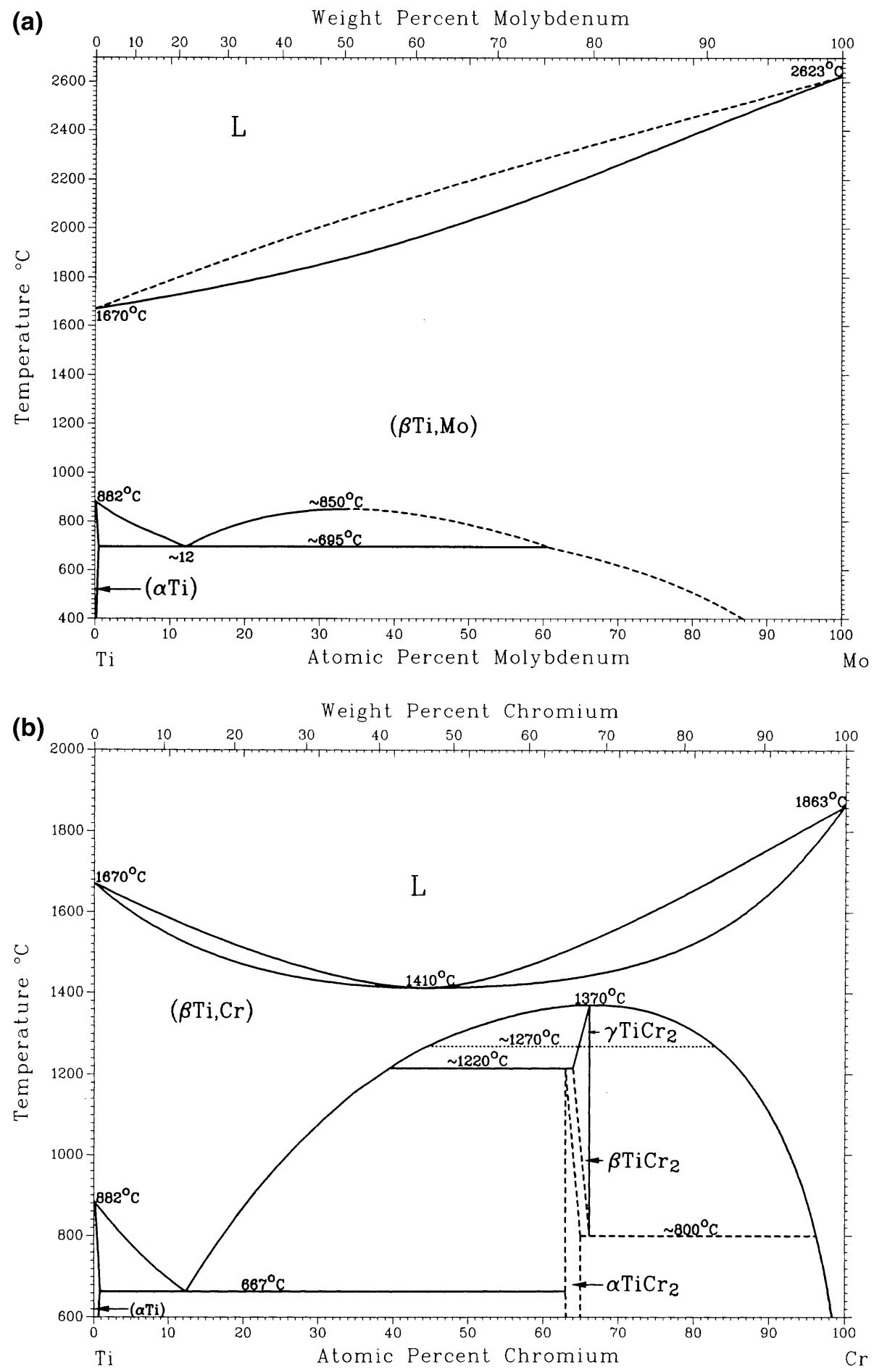

Fig. 1. Typical binary phase diagrams illustrating types of beta phase stabilization: (a) Ti-Mo isomorphous type and (b) Ti-Cr eutectoid type. ${ }^{13}$

beta-phase stabilized through macroalloying, as illustrated by the typical binary phase diagrams in Fig. 1. The addition to isomorphous beta-phase stabilizers, such as V, Zr, Nb, Mo, Hf, Ta, and Re, expand the $\beta$ phase field, thereby shifting the $\beta /(\alpha+\beta)$ phase boundary to lower temperatures. This is illustrated by prototypical Ti-Mo binary system in Fig. 1a. The beta phase may likewise be stabilized by elements such as $\mathrm{Cr}, \mathrm{Mn}, \mathrm{Fe}, \mathrm{Co}, \mathrm{Ni}, \mathrm{Cu}$ and $\mathrm{W}$ (and the precious metals), which exhibit a eutectoid reaction between the beta phase and an ordered compound (Fig. 1b). Collings ${ }^{11}$ discussed titanium alloy classification in detail, although much of present-day titanium alloy classification can be traced to Molchanova. ${ }^{12}$ Depending on the degree of alloying and thermomechanical processing path, considerable 
control over the balance of alpha and beta phases in the final product is possible, which then permits tailoring to desired property sets emphasizing strength, toughness, or fatigue properties.

A proper review requires a definition of beta titanium alloys because there is a continuum of beta phase stabilization, and the distinction between alpha-beta and beta alloys has been subjective. Jaffee $^{14}$ separated beta-stabilized chemistries into types of increasing beta-stability termed, alphamatrix alpha-beta $\rightarrow$ beta-matrix alpha-beta $\rightarrow$ unstable (metastable) beta $\rightarrow$ practically stable beta $\rightarrow$ stable beta. In this context, metastable beta alloys were defined as those consisting of beta phase after quenching but decomposing to alpha and stable beta phases on annealing or working in the alpha-beta field. "Practically stable" beta alloys were those sufficiently stable that they may be used for service but will transform upon heating to a sufficient temperature, and "Stable" beta alloys are those for which the beta transus lies below room temperature.

Duerig and Williams ${ }^{1}$ used the following operational definition of a beta titanium alloy: "A $\beta$-Ti alloy is any titanium composition which allows one to quench a very small volume of material into ice water from above the material's $\beta$-transus temperature without martensitically decomposing the $\beta$-phase." Another working definition of beta titanium alloy is: "An alloy sufficiently rich in beta stabilizing solutes that the beta phase can be retained untransformed by quenching from the beta phase field to room temperature." ${ }^{10}$ While the quenching definition has persisted, issues with this definition are: (I) the retained beta phase is metastable in nearly all commercial alloys, (II) this definition ignores formation of metastable athermal omega phase during quenching, and (III) it does not consider kinetics of beta phase decomposition during quenching, so the section thickness is not taken into account (a major issue in production applications). Notwithstanding these caveats, retaining beta on quenching still constitutes the accepted definition of beta titanium alloys. ${ }^{15}$ To address the limits associated with this definition, beta alloys are subdivided into solute-lean and solute-rich compositions, defining the former as those that formed athermal omega $\left(\omega_{\mathrm{a}}\right)$ during quenching and the latter as those that form thermal $\omega$ on aging. Froes ${ }^{2}$ and Bania ${ }^{4}$ applied the same definition, and Bania correlated this boundary to a delineation of molybdenum equivalent (Mo-Eq) at about $10 \mathrm{wt} . \%$, where:

$$
\begin{aligned}
\mathrm{Mo}-\mathrm{Eq}= & \mathrm{Mo}+0.67 * \mathrm{~V}+0.44 * \mathrm{~W}+0.28 * \mathrm{Nb} \\
& +0.22 * \mathrm{Ta}+2.9 * \mathrm{Fe}+1.6 * \mathrm{Cr} \\
& -1.0 * \mathrm{Al}
\end{aligned}
$$

all in weight percent. ${ }^{4}$ The coefficients of this equation estimate the contribution of each transi- tion element in retaining the beta phase on quenching and assumes simple additivity, after Molchanova. ${ }^{12}$ Since the critical concentration to retain the beta phase on quenching in the Ti-Mo binary was estimated at approximately $10 \mathrm{wt} . \% \mathrm{Mo}$, this equation provides a method of collapsing complex chemistries into a single stability parameter benchmarked to an equivalent Mo content. Note that Bania's expression includes a factor for $\mathrm{Al}$ to compensate for the opposing effect of alpha stabilizers. This is practical and adopted here as well, although the separate effect of alpha stabilizers, such as $\mathrm{Al}, \mathrm{Sn}, \mathrm{O}$, and $\mathrm{N}$, may be likewise accounted for by a separate "Al-Eq" expression: ${ }^{16}$

$$
\mathrm{Al}-\mathrm{Eq}=\mathrm{Al}+\mathrm{Zr} / 6+\mathrm{Sn} / 3+10(\mathrm{O}+\mathrm{N})
$$

About the same time, Eylon et al. ${ }^{5,6}$ suggested reasonable delineations at $8 \mathrm{wt} . \%$ and $30 \mathrm{wt} . \% \mathrm{Mo}-\mathrm{Eq}$, whereby alloys with values from $8 \mathrm{wt} . \%$ to $30 \mathrm{wt} . \%$ were termed "metastable beta" and those below 8 wt.\% were considered "beta-rich alpha-beta," and those above 30 identified as "stable beta." Because a number of leaner titanium alloys contain sufficient beta stabilizer to confer, relative to Ti6Al4V, improved formability and forgeability [a result of a greater number of active slip systems in the bcc phase relative to the hexagonal close-packed (hcp) phase], a good heat treatment strengthening response, and a lower beta transus temperature, they are often included in beta titanium alloy reviews. These include the "nearbeta" alloys, roughly identified as having Mo-Eq values of 5-10\%, and sometimes leaner compositions, characterized as the "beta-rich alpha-beta" (Mo$\mathrm{Eq}<5$ ). These can include alloys such as Ti-Beta III, Beta CEZ, and Ti-17 (Ti-17 is employed as an engine mount fitting for the GE90 engine on the Boeing $777^{17}$ ), and the latter, Ti6246, an important deephardenable, moderate-temperature alloy.

More heavily alloyed chemistries have high MoEq values and result in deeper hardenability, which is necessary for thick section applications, but also generally they have increased density, cost, and ingot segregation tendencies. The most stable production beta alloy is alloy $\mathrm{C}$, which has a Mo-Eq of 47.5. Distinctions between the Mo-Eq boundaries for alloys termed beta-rich alpha-beta, near-beta, metastable beta, and stable beta are subjective and vary depending on source.

Approximate beta titanium alloy categories are indicated in the pseudobinary Ti-X phase diagram in Fig. 2, which also identifies some of the stable and metastable phases possible in metastable beta systems. Figure 3 plots the Mo-Eq values for a number of reported titanium alloys. Although it is not rigorous, especially when applied to complex multicomponent alloys, the Mo-Eq value remains a convenient parameter for ranking the beta phase stability of various compositions and will be referred to in these terms below. 


\section{DEVELOPMENT HISTORY}

Beta-stabilized titanium alloys were discussed as a distinct class by Jaffee as early as $1955 .{ }^{14}$ By the 1960 s, numerous compositions had been introduced in an attempt to exploit the performance potential for applications mostly of a military nature (e.g., pressure vessels and rocket motor cases). ${ }^{18}$ Following a flurry of initial developments, Ti-13V-11Cr-3Al emerged as the high-strength, heat-treatable airframe alloy for the

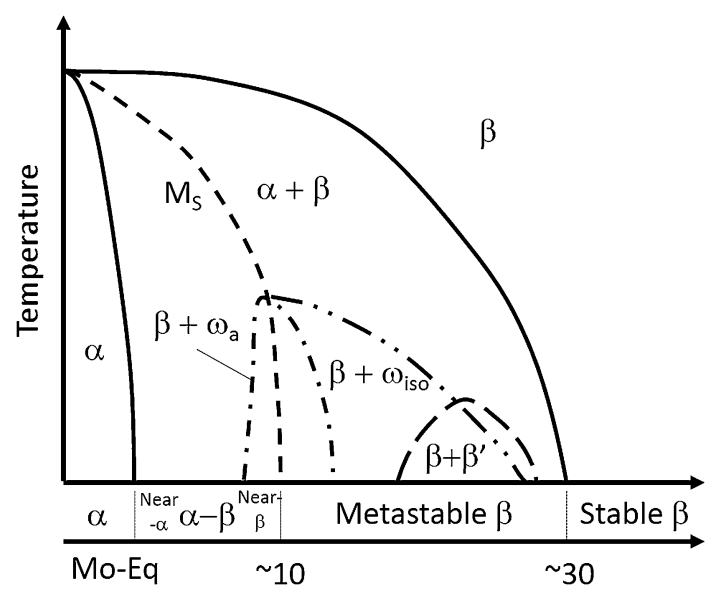

Fig. 2. Pseudobinary Ti-beta isomorphous phase diagram, after Ref. $1 \mathrm{Mo}-\mathrm{Eq}=\mathrm{Mo}+0.67^{\star} \mathrm{V}+0.44^{\star} \mathrm{W}+0.28^{\star} \mathrm{Nb}+0.22^{\star} \mathrm{Ta}+2.9^{\star} \mathrm{Fe}+$ $1.6^{*} \mathrm{Cr}-1.0^{*} \mathrm{Al}(\mathrm{wt} . \%){ }^{4}$
SR-71 Blackbird. ${ }^{19}$ By the 1980s, it had been adapted to springs for multiple aircraft actuation systems. ${ }^{17}$ However, Ti-13V-11Cr-3Al was difficult to produce and displayed an inconsistent heat treat response. Eventually it was replaced by the more forgiving Ti3AI-8V-6Cr-4Mo-4Zr (Beta C) as the preeminent choice for aircraft springs. For some time, beta alloy development was somewhat dormant, ${ }^{20}$ but by the 1980s there had been sufficient work to warrant a TMS symposium devoted specifically to the topic. ${ }^{1}$ Several beta titanium alloys were committed to commercial airframe applications by this time, principally, Ti-10V-2Fe-3Al, Ti-15V-3Al-3Sn-3Cr and Beta C in the United States and Europe, and Ti-5Al-5V-5Mo$1 \mathrm{Cr}-1 \mathrm{Fe}$ (VT-22) in Russia.

All four of these alloys continue to be used today, ${ }^{3,5}$ with the addition of Beta $21 \mathrm{~S}$ for elevated temperature applications on the Boeing 777 engine nozzle in 1993. ${ }^{3,17,21}$ Besides exhibiting good oxidation resistance and formability, Beta 21S has excellent resistance to hot aircraft hydraulic fluid ("Skydrol"), ${ }^{22}$ which became an important selection criterion. Alloy C, the alloy closest to a true stable beta composition, was baselined for the F-22 thrustvectored nozzle system in the early 1990 s for its reported burn resistance properties, and it has continued to find production applications. ${ }^{23}$ In the late $1990 \mathrm{~s}$, Ti-5Al-5V-5Mo-3Cr-0.5Fe (Ti-5553) was introduced by VSMPO ${ }^{24,25}$ as an evolution of the long-standing VT-22 Russian alloy and commercialized for major die forging applications on the

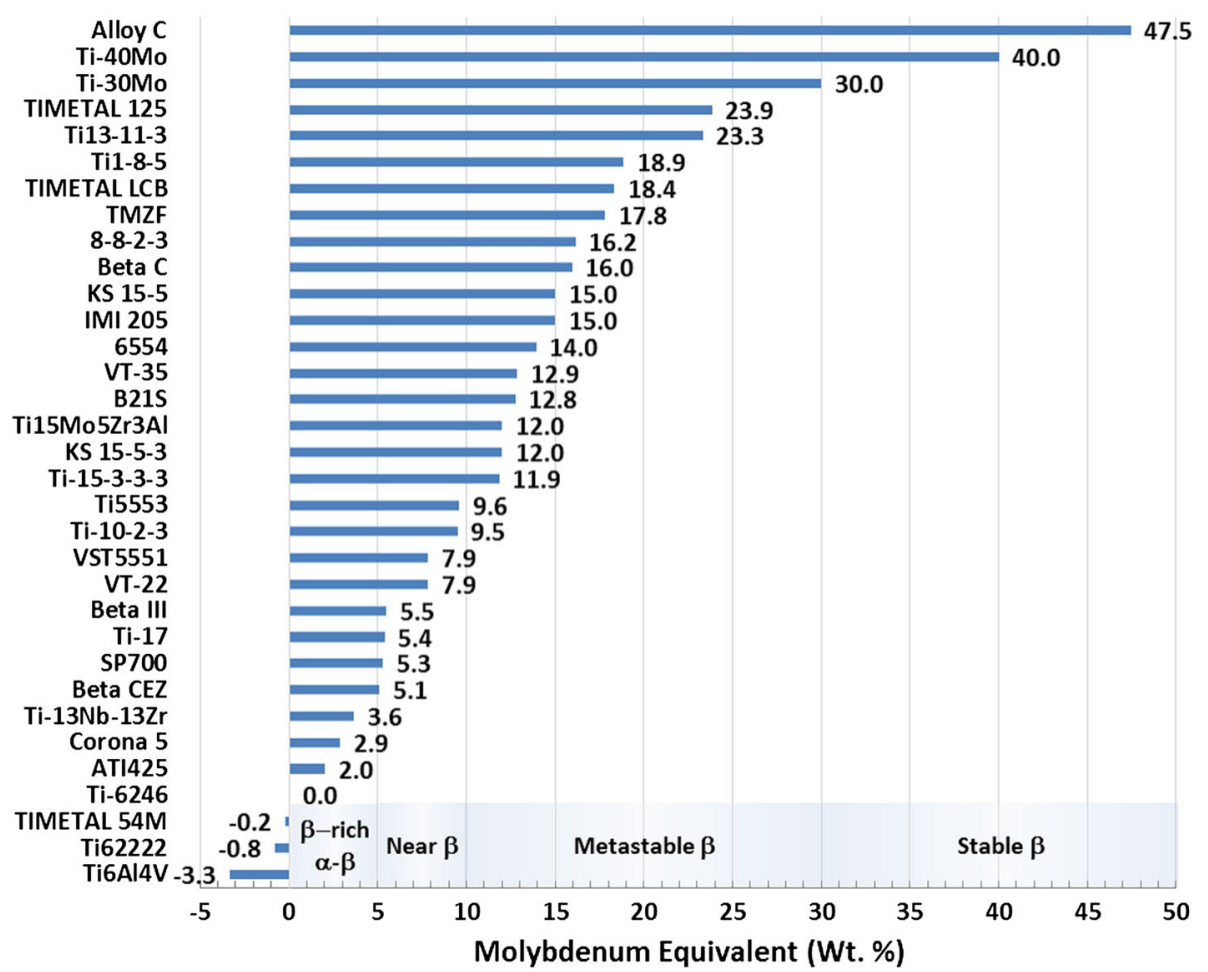

Fig. 3. Selected beta titanium alloys and their molybdenum equivalent values. Mo-Eq $=\mathrm{Mo}+0.67^{\star} \mathrm{V}+0.44^{\star} \mathrm{W}+0.28^{\star} \mathrm{Nb}+0.22^{\star} \mathrm{Ta}+2.9^{\star}-$ $\mathrm{Fe}+1.6^{*} \mathrm{Cr}-1.0^{\star} \mathrm{Al}$ (all concentrations in wt.\%), after Ref. 4 Titanium alloys at the bottom of the diagram are included for comparison purposes. 
Table I. Beta titanium aerospace alloys in current production

\begin{tabular}{|c|c|c|c|c|c|c|c|}
\hline Alloy ID & $\begin{array}{c}\text { Industry } \\
\text { spec }\end{array}$ & Developed by & $\begin{array}{c}\underset{\text { Nominal }}{\text { composition }} \\
\text { (wt.\%) }\end{array}$ & $\begin{array}{c}\text { Principal } \\
\text { product } \\
\text { form }\end{array}$ & $\begin{array}{c}\text { Heat } \\
\text { treatments }\end{array}$ & 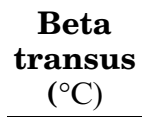 & Mo-eq (\%) \\
\hline Ti-10V-2Fe-3Al & AMS4983/4 & TIMET, 1971 & $10 \mathrm{~V} 2 \mathrm{Fe} 3 \mathrm{Al}$ & Forgings & STA & $790-805$ & 9.5 \\
\hline $\begin{array}{l}\text { Ti-5553 } \\
\text { (and Ti55531) }\end{array}$ & Proprietary & VSMPO, 1997 & 5Al5V5Mo3Cr0.5Fe & Forgings & STA, BASCA & $855-870$ & 9.6 \\
\hline $\begin{array}{l}\text { Ti-15V-3Al- } \\
3 \mathrm{Sn}-3 \mathrm{Cr}\end{array}$ & AMS 4914 & TIMET, 1978 & 15V3Cr3Al3Sn & Strip & STA & $750-770$ & 11.9 \\
\hline Beta 21S & AMS 4897 & TIMET, 1989 & $15 \mathrm{Mo} 2.7 \mathrm{Nb} 3 \mathrm{Al} 0.2 \mathrm{Si}$ & Strip & STA, STOA & $795-810$ & 12.8 \\
\hline Beta C & AMS 4957 & RTI, 1969 & 3Al8V6Cr4Mo4Zr & Spring wire & STA & 730 & 16.0 \\
\hline Alloy C & No industry spec & P\&W, 1990 & $35 \mathrm{~V} 15 \mathrm{Cr}$ & Sheet & Ann & unknown & 47.5 \\
\hline
\end{tabular}

Boeing 787 Dreamliner in the 2000s. Ti-5553 offers a modest improvement in strength and toughness over Ti-10-2-3, but it was, to a large extent, selected for its more tolerant processing which ultimately allowed it to be more competitive. Ti-5553 is the most recent addition to the list of commercialized beta titanium alloys for airframe applications.

Table I lists six aerospace beta titanium alloys in production, along with some background data. ${ }^{1-3,5,9,24,26-29}$ These are Ti-10V-2Fe-3Al, Ti-15V3Al-3Sn-3Cr, Beta C, Beta 21S, Ti-5Al-5V-5Mo-3Cr$0.5 \mathrm{Fe}$ (Ti-5553) (and its European variant, Ti-5Al$5 \mathrm{~V}-5 \mathrm{Mo}-3 \mathrm{Cr}-1 \mathrm{Zr}$ ), and alloy $\mathrm{C}$, and all of them are discussed below. Significant resources have been expended to design other, more cost-effective beta alloys, particularly Beta CEZ, Beta III (Mo$\mathrm{Eq}=5.5)$, SP700, and Beta LCB. . $^{4,9,9,10,17,30,31}$ All except Beta III were developed for reduced cost by taking advantage of iron as an inexpensive beta stabilizer. However, these alloys have had difficulty displacing well-established peers in the aerospace market ${ }^{6}$ and are not addressed in detail herein.

\section{COMMON FEATURES OF INDUSTRIAL BETA TITANIUM ALLOYS}

\section{Chemistry}

The alloys shown in Table I share some common characteristics, including chemical composition, as summarized in Table II. All contain aluminum as the principal substitutional alpha-stabilizer except for Alloy C. Aluminum is beneficial in that it provides solid-solution strengthening for the alpha phase while reducing density and formulation costs. Its ready rejection from the beta phase enhances alpha precipitation. It raises the beta transus, which can be important if deformation below the transus is desirable. Among the isomorphous beta stabilizers, vanadium and molybdenum are common additions due to good beta stabilization factors, costeffective master alloys, and low solidification segregation tendencies. However, vanadium is not a good alloying choice for elevated temperature oxidation resistance, ${ }^{21}$ and therefore, it is deliberately not a component of Beta $21 \mathrm{~S}$, an alloy developed for elevated temperature service (although it is present in high concentrations in alloy $\mathrm{C}$, albeit, for different reasons, discussed below). Among the eutectoid formers, chromium and iron are beta stabilizers of choice, exhibiting a eutectoid decomposition of the type $\beta \rightarrow \mathrm{Ti}_{x} \mathrm{M}_{y}+\alpha$. These elements are the most efficient solid-solution strengtheners ${ }^{10}$ and cost-effective additions, within limits, in titanium alloy design. Iron is a powerful beta stabilizer and a rapid (anomalous) diffuser, and it is thus not desirable for creep-driven applications. Iron and chromium also promote a wider mushy zone on solidification, leading to greater constitutional undercooling, coring, and potentially gross segregation during vacuum arc remelting that cannot be reasonably eliminated by homogenization. ${ }^{32-34}$ This necessitates more control during ingot melting to promote homogeneous melts via controlled solidification rates. Therefore, iron and chromium are limited to about 2 wt.\% and 6 wt.\%, respectively, in production vacuum arc remelting (VAR) ingots. ${ }^{35,36}$ This does not preclude the use of smaller ingots to produce ${ }^{37}$ for example, fastener wire stock, but it does explain to a large extent the absence of Ti-1Al$8 \mathrm{~V}-5 \mathrm{Fe}$ and $\mathrm{Ti}-13 \mathrm{~V}-11 \mathrm{Cr}-3 \mathrm{Al}$ from modern technical titanium alloys.

\section{Reduced Beta Transus Temperatures and Flow Stresses}

Another common feature of beta titanium alloys is a reduced beta transus temperature, compared with alpha/beta titanium alloys. The beta transus temperature can be estimated from the Mo-Eq value, as noted by the plot in Fig. 4. Relative to standardgrade Ti6Al4V, most beta alloys have $100^{\circ} \mathrm{C}$ to $200^{\circ} \mathrm{C}$ lower transus temperatures, permitting reduced thermomechanical processing temperatures and allowing for lower flow stresses (due to higher beta phase content, or beta processing, since the beta phase is generally softer than the alpha phase). This is particularly evident in the case of Ti-10V$2 \mathrm{Fe}-3 \mathrm{Al}$, forgeable at $760^{\circ} \mathrm{C},{ }^{38,39}$ which was developed and marketed in part for its good forgeability and ability to achieve more net shapes than typical alpha-beta alloys. ${ }^{33,38}$ Comparative flow stress data 

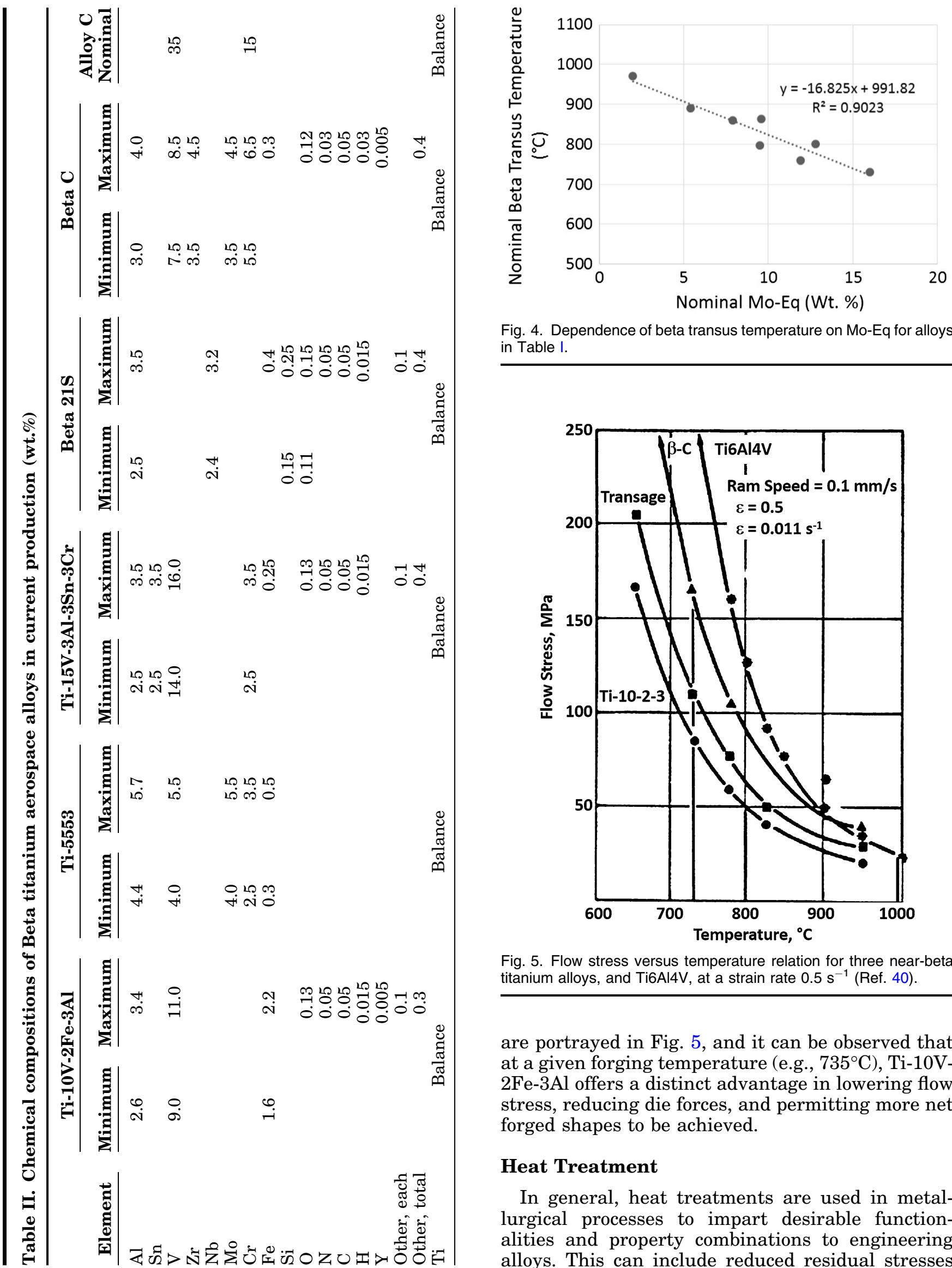

Fig. 4. Dependence of beta transus temperature on Mo-Eq for alloys in Table I.

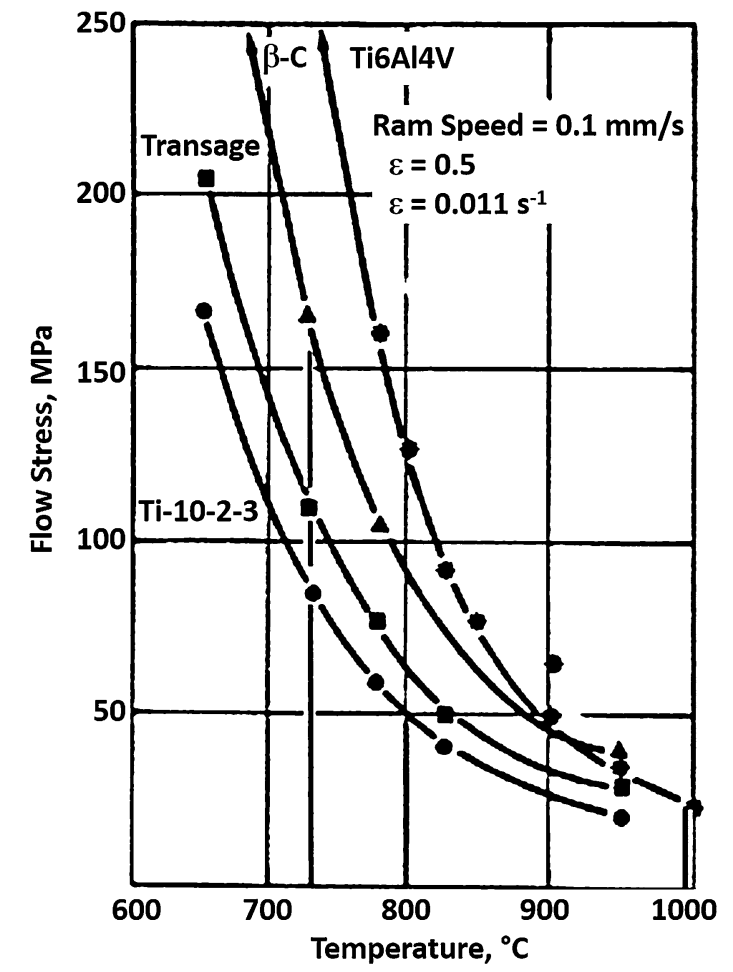

Fig. 5. Flow stress versus temperature relation for three near-beta titanium alloys, and Ti6Al4V, at a strain rate $0.5 \mathrm{~s}^{-1}$ (Ref. 40).

are portrayed in Fig. 5, and it can be observed that at a given forging temperature (e.g., $735^{\circ} \mathrm{C}$ ), Ti-10V$2 \mathrm{Fe}-3 \mathrm{Al}$ offers a distinct advantage in lowering flow stress, reducing die forces, and permitting more net forged shapes to be achieved.

\section{Heat Treatment}

In general, heat treatments are used in metallurgical processes to impart desirable functionalities and property combinations to engineering alloys. This can include reduced residual stresses 
Table III. Solution treatment and age conditions for selected commercial beta titanium alloys

\begin{tabular}{|c|c|c|c|c|c|c|c|}
\hline Alloy ID & $\begin{array}{c}\text { Beta } \\
\text { transus }\left({ }^{\circ} \mathrm{C}\right)\end{array}$ & $\begin{array}{c}\text { Solution } \\
\text { temperature } \\
\left({ }^{\circ} \mathrm{C}\right)\end{array}$ & $\begin{array}{l}\text { Solution } \\
\text { time }(h)\end{array}$ & $\begin{array}{l}\text { Quench } \\
\text { medium }\end{array}$ & $\begin{array}{c}\text { Age } \\
\text { temperature } \\
\left({ }^{\circ} \mathrm{C}\right)\end{array}$ & $\begin{array}{c}\text { Age } \\
\text { time (h) }\end{array}$ & References \\
\hline Ti-5553 & $820-880$ & $740-860$ & 1 & Air & $550-677$ & 8 & 47 \\
\hline Ti-15V-3Al-3Sn-3Cr & $750-770$ & $788-843$ & $.05-0.5$ & Air & $482-538$ & $8-16$ & 48 \\
\hline Ti-10Al-2Fe-3Al & $790-805$ & $760-780$ & 1 & Water & $495-525$ & 8 & 29 \\
\hline Beta 21S & $795-810$ & $816-899$ & $.05-0.5$ & Air & 593 or $690+649$ & 8 & $9,49,50$ \\
\hline Beta C & $715-740$ & $815-925$ & 1 & Water & $455-540$ & $8-24$ & 29 \\
\hline Alloy C & na & 850 & 2 & na & na & & 51 \\
\hline
\end{tabular}

na $=$ not applicable.

(stress relieving), improved fabricability (annealing), and targeted degrees of strength [solution treatment and aging (STA)], ductility, toughness, durability, fatigue, and corrosion resistance [solution treat and overage (STOA)]. In the case of beta alloys, stress relieving and annealing are generally accomplished in tandem with strengthening thermal treatments, such as STA. Intermediate process anneals may also be required for large reductions (such as in sheet or fastener wire manufacture).

With the exception of Alloy C, all beta alloys to date are amenable to STA thermal treatment per the established conditions tabulated in Table III. This treatment produces a fine dispersion of secondary alpha precipitates as the principal strengthening phase. ${ }^{2}$ Interestingly, because the alpha/beta interface, and not the hcp alpha phase per se, provides the effective obstacle to dislocation motion (Orowan bypass mechanism), the alpha-toalpha interparticle spacing (d) may be utilized to estimate tensile yield strength, according to: ${ }^{41}$

$$
\text { TYS }(\mathrm{MPa})=850+70 / \mathrm{d}^{-1}(1 / \mu \mathrm{m})
$$

Other heat treatments are also utilized, such as the duplex, triplex, beta anneal, slow-cool, and age $(\text { BASCA })^{42}$ to achieve different property balances, via different aspect ratios, volume fractions, and distributions of the alpha phase.

Solution treatment in beta alloys follows conventional solutionizing, supersaturation, and precipitation theory, although solution treatment may be accomplished by either heating above the transus (usually for more heavily stabilized alloys) or just below the transus, which allows for enrichment of the beta phase according to the lever law. ${ }^{43}$ Metastable phases, $\omega$ and $\beta^{\prime}$, may be precursors to alpha precipitation at intermediate Mo equivalents (see Fig. 2) and lower aging temperatures. These phases are coherent and easily sheared, leading to planar slip and reduced ductility and fatigue strength (although not always-Ref. 44 reported that omega phase can significantly slow fatigue crack propagation in Ti-10-2-
3). Commercial heat-treatment practices are designed to either avoid such phases via the use of sufficiently high aging temperatures and longer age times, or for the more stable alpha to replace the metastable forms via sympathetic nucleation to create a more homogeneous distribution of particles. ${ }^{30}$ Longer aging times also reduce property scatter in the STA condition. ${ }^{45,46}$

\section{Hardenability}

Hardenability is a measure of the section size that can be strengthened after a heat-treatment process. For ferrous alloys, this is usually the depth to which martensite can be formed on quenching and is defined by a critical quench rate, or an ideal critical diameter, which is the diameter of an ideally quenched round that will transform to $50 \%$ martensite at the center in a standard test such as the Jominy End Quench. ${ }^{52}$

In the case of beta titanium alloys, hardenability may be defined as the ability to produce a significant age-hardening response from supersaturated $\beta$ phase. Attaining a useful metastable condition in the beta phase requires that (I) $\alpha^{\prime}$ martensite not be formed and (II) that diffusional alpha not precipitate during the quenching process. To avoid martensite, sufficient beta stabilizers must be present to depress the $M_{\mathrm{s}}$ temperature to below the quench medium temperature (see Fig. 2). Avoidance of alpha precipitation depends on retarding the precipitation kinetics, generally via macroalloying of slow diffusers (e.g., V, Mo, and Nb). Both of these effects are encouraged by higher beta stabilizer content, although this only works to a point because as the beta transus temperature falls, the ability to subsequently age harden will be likewise reduced by unacceptably slow diffusion rates at lower temperatures. Hence, there is an optimum level of beta stabilizers in which both quenching to a supersaturated state and aging are practical.

The above description is further complicated by a couple other aspects. One is the opportunity and practice of subtransus solution treatment in leaner 


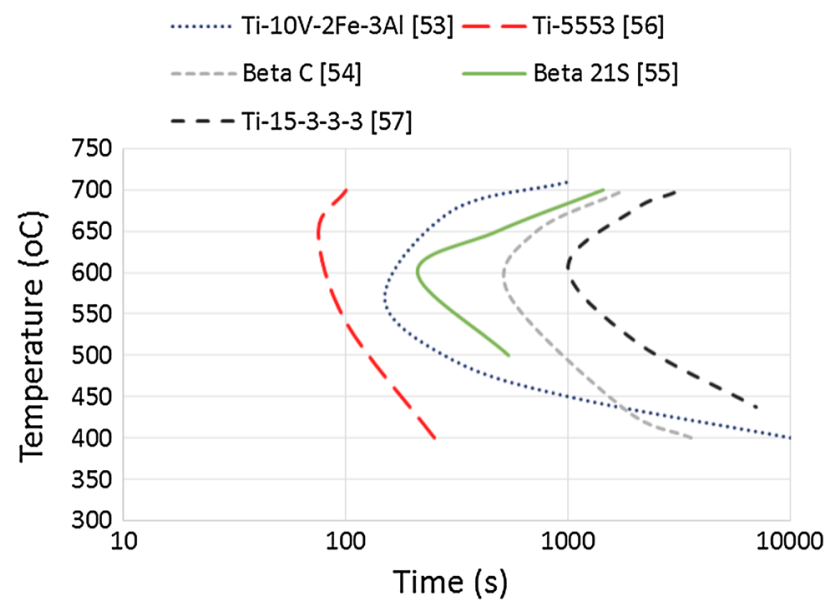

Fig. 6. TTT C-curves for initial $\alpha$ precipitation (lower-temperature metastable phase reactions are omitted for clarity) in selected beta titanium alloys following quenching from respective solution treatment temperatures. ${ }^{53-57}$ Note that Ti-5553 and Ti-10V-2Fe-3Al are subtransus solution treated while the other alloys are supertransus solution treated prior to quenching.

beta alloys. This approach permits solute enrichment of the beta phase in exchange for a minor volume fraction of primary alpha. The resulting two-phase mixture is also useful in retarding grain growth during subsequent thermal operations. The other aspect concerns products of significant gauge thickness, in which the local cooling rate differs substantially between the surface and center, and between thin and thick sections. This parameter is important for heavy section applications because it quantifies the minimum local cooling rate required to retain $\beta$ phase and becomes a practical extension of the "quenchability" definition of a metastable beta alloy described above. One way to characterize hardenability is via use of continuous-coolingtransformation (CCT) and time-temperaturetransformation (TTT) diagrams. CCTs are most appropriate. However, paradoxically, CCTs are not generally available for technical beta alloys (this is an ideal area for future experimental work). Experimental TTT diagrams have been published for some common beta titanium alloys ${ }^{53-58}$ and can provide an indicator of relative aging kinetics, once a structure is quenched to form supersaturated beta. These are co-plotted in Fig. 6.

Figure 6 illustrates considerable kinetic differences between the five predominant beta titanium alloys during isothermal aging of quenched microstructures. The curve positions can shift depending on the degree of stored strain energy and should not be taken as exact. Although beta decomposition reactions begin for Ti-5553 and Ti-10-23 within a couple minutes, more heavily stabilized alloys can take up to ten times that long to begin. This can provide a considerable advantage when heat treating thick sections and large components. Ironically, the more sluggish alloys are used mainly in thinner product applications, such as wire and sheet, for their good formability.

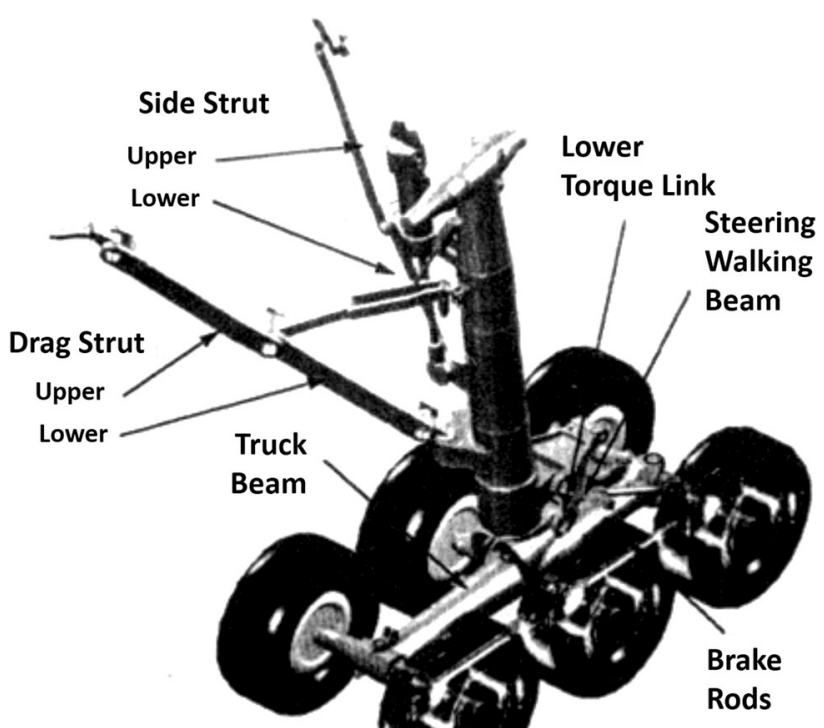

Fig. 7. Ti-10V-2Fe-3Al forging applications on the Boeing 777 main landing gear. $^{3}$

A CCT diagram has been published for beta-solution treated Ti-5553. ${ }^{56}$ This diagram suggests that reaction start times for Ti-5553 are significantly extended during cooling operations compared with isothermal annealing and supports production practices that permit air cooling after solution treatment. Such behavior is remarkably different from published TTT curves. ${ }^{56,58}$ This remains an important area of future work to better define production operating windows and margins.

\section{CURRENT PRODUCTION BETA TITANIUM ALLOYS}

\section{Ti-10V-2Fe-3Al (Ti-10-2-3)}

The compositional range containing the Ti-10-2-3 chemistry was patented by TIMET in 1974, with the intention to provide an alloy with an improved combination of deep hardenability, good strength and ductility, and fracture toughness relative to Ti6Al4V. ${ }^{59,60}$ After the application of Ti-13V-11Cr$3 \mathrm{Al}$ to the SR-71, Ti10-2-3 became the most important and visible application of beta titanium alloys in the aerospace industry. 8,33,34,46 This was in large part due to the commercial forging applications on the Boeing 777 landing gear (see Fig. 7), although Ti-10-2-3 got its start in airframe applications in 1980 when it was downselected by Boeing for the 757 after a set of demanding performance requirements were established, such as $1240 \mathrm{MPa}(180 \mathrm{ksi})$ UTS and a KIc of $44 \mathrm{MPa} \sqrt{\mathrm{m}}$ (40 ksi $\sqrt{\mathrm{in}}$ ), to support new aircraft designs. ${ }^{39}$ The 777 landing gear applications saved $270 \mathrm{~kg}$ (595 lbs) per aircraft ${ }^{17}$ and were applied to all major gear components with the exception of the inner and outer cylinders. ${ }^{10}$ Applications later expanded to commercial Airbus 
transports, military transports, fighters, and helicopters.

\section{Chemical Composition and Processing}

Ti-10-2-3 is a borderline metastable beta alloy according to the Mo-Eq value in Fig. 3 but offers the essential features of the more highly alloyed beta alloys (except air quenchability), such as good heattreatment response and low flow stresses, as shown in Fig. 5. The composition of Ti-10-2-3 is shown in Table II, where vanadium and iron figure as the prominent beta stabilizers. The nominal 2 wt.\% iron promotes good hardenability and is at the limit within which microsegregation is considered manageable (although challenges were noted before melting practices were stabilized ${ }^{33}$ ). A nominal aluminum content of $3 \mathrm{wt}$.\% produces sufficient alpha phase to provide the hardening reaction, while oxygen is limited to $0.13 \mathrm{wt} . \%$ to maintain toughness at the relatively high strength levels. ${ }^{34,60,61}$

Ti-10-2-3 ingot is produced by multiple melting steps, the first of which may be from a consumable or a nonconsumable electrode, or a hearth melting process, followed by a second melt that must conform to vacuum arc remelt practice. ${ }^{62} \mathrm{~A}$ modest tendency for microsegregation in the form of "beta fleck" defects is understood by producers, and melt and heat-treatment practices have been developed to minimize the potential for such issues. ${ }^{36} \mathrm{Mi}$ crosegregation is more of an issue for property variability than for fatigue crack initiation. ${ }^{33}$

From a fabrication standpoint, Ti-10-2-3 is considered one of the most forgeable titanium alloys, with low flow stresses and a high resistance to edge cracking, allowing greater reductions between reheats. This reduces the cleanup required between forging operations to much less than that for Ti-6Al$4 \mathrm{~V}$, improving yield and, probably most important, reducing labor-intensive conditioning operations. The significantly lower beta transus (relative to alpha-beta alloys) reduces the energy required to heat input stock to the forge temperature and extends die life, both contributing to reduced final component cost. These characteristics enhance the forger's ability to fabricate intricate and precision forgings requiring minimal subsequent machining. ${ }^{33,34,63}$

Thermomechanical processing of Ti-10-2-3 is particularly important to property development because it relies on development of the optimum primary alpha morphology and volume fraction to ensure a minimum toughness. Forgings are typically beta forged to a degree sufficient to promote recrystallization and then alpha-beta forged at $10-25^{\circ} \mathrm{C}$ below the transus. Ti-10-2-3 recrystallizes more readily than other beta alloys due to the absence of slow diffusers $(\mathrm{Mo}, \mathrm{Nb})$ and presence of a rapid diffuser, iron. ${ }^{10}$ The target amount of alphabeta forging to balance ductility and fracture toughness is between approximately $10-25 \%$ reduction, typically $20 \%$, because insufficient

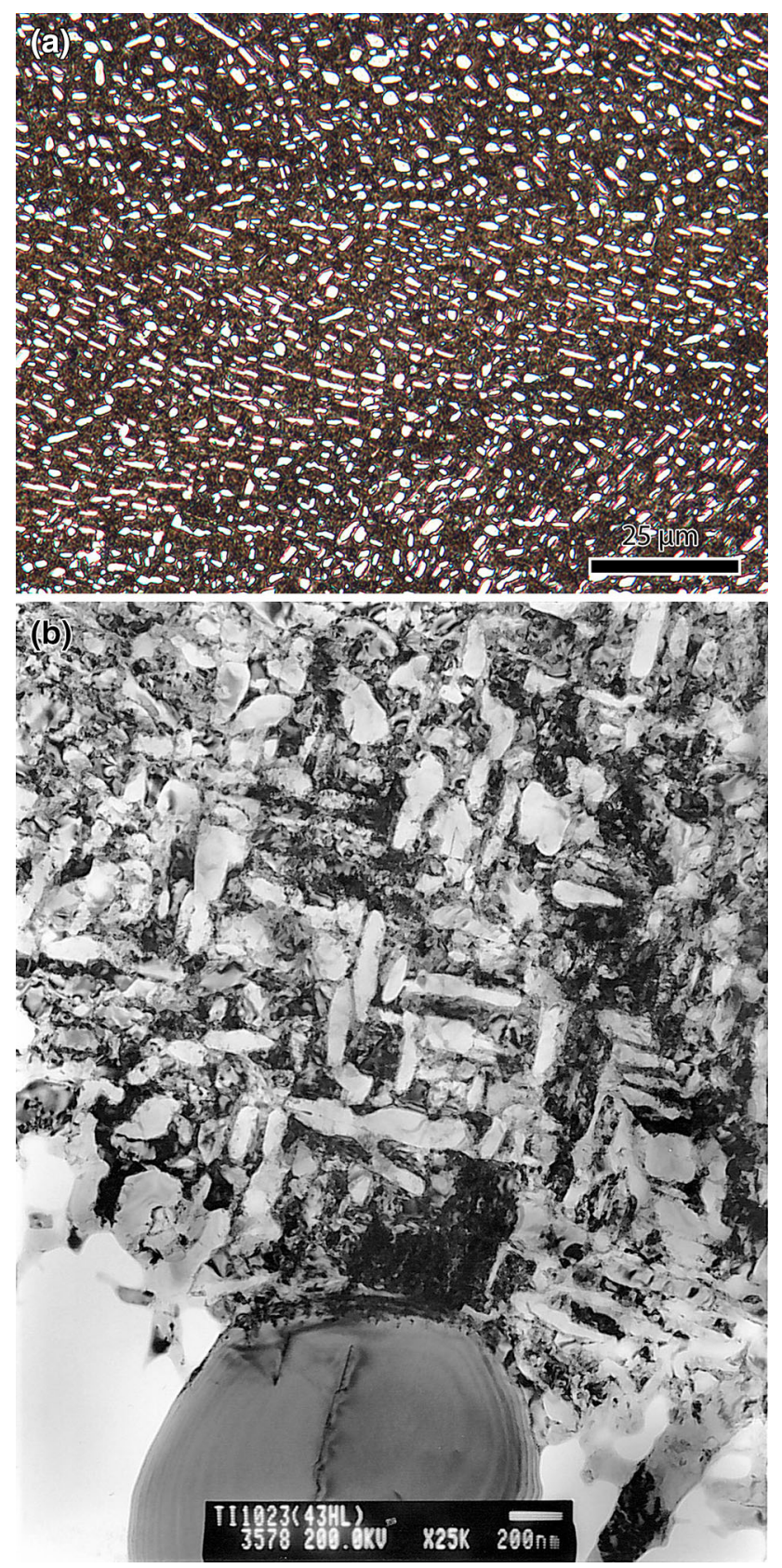

Fig. 8. Microstructure of Ti-10-2-3 forging, STA condition: (a) Light optical photomicrograph showing elongated primary alpha (light) in an aged beta matrix (dark). (b) Transmission electron photomicrograph bright-field image showing a globular primary alpha particle (bottom) and a high volume fraction of very fine aged alpha precipitates (top).

globularization of the primary alpha will impact elongation, whereas too much limits fracture toughness. ${ }^{33,34,64}$ It also serves to break up the grain boundary alpha phase. A typical microstructure, shown in Fig. 8, will contain a large volume fraction of elongated (aspect ratio greater than 3:1) primary alpha in a matrix of aged beta (etching dark).

Several solution-treated and aged heat treatments have been developed to achieve particular 
property balances in Ti-10-2-3, resulting in ultimate tensile strengths ranging from an STOA condition at $965 \mathrm{MPa}(140 \mathrm{ksi})$ to single-step STA at $1241 \mathrm{MPa}(180 \mathrm{ksi}){ }^{61,65,66}$ The alloy offers a wide range of strength-toughness combinations that can

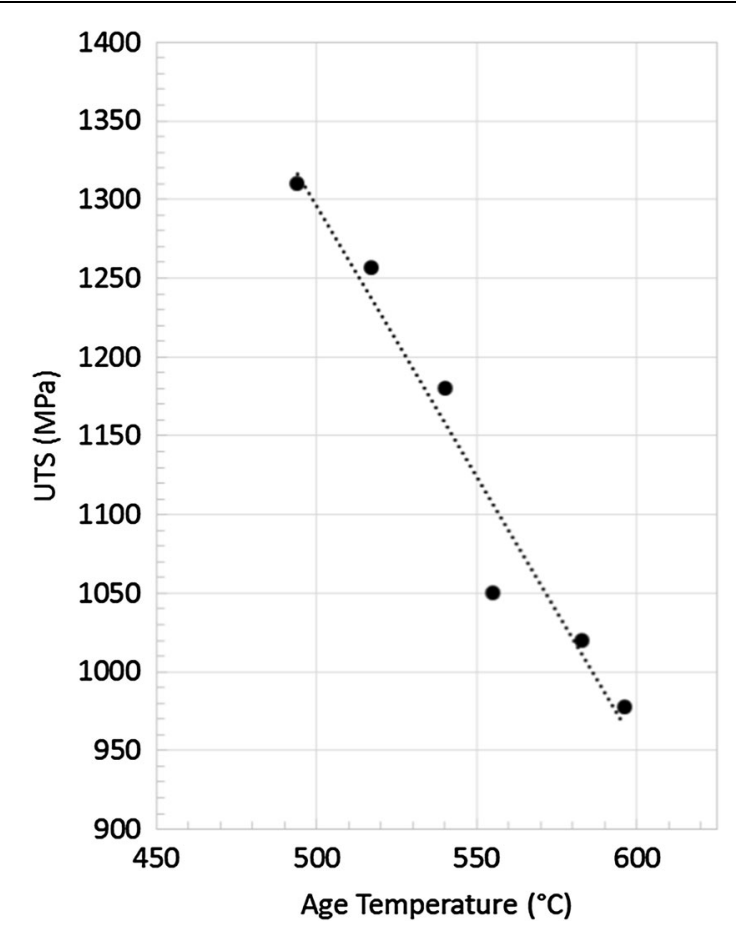

Fig. 9. Aging curve for Ti-10V-2Fe-3Al, solution treated at $750^{\circ} \mathrm{C}$ $\left(1385^{\circ} \mathrm{F}\right)$, water-quenched and aged for $8 \mathrm{~h}$ at indicated temperature. ${ }^{34}$ be achieved through variations in heat-treatment parameters. ${ }^{63}$ This is demonstrated by the plot in Fig. 9, which shows the dependence of ultimate tensile strength on aging temperature. ${ }^{34}$

One caveat of heat treating Ti-10-2-3 is that water quenching is required to retain sufficient supersaturated beta to generate acceptable mechanical properties, and this limits the useful section size at heat treatment to approximately $76 \mathrm{~mm}$ (3 in.). Water quenching also can create sizeable residual stresses that impact dimensional stability during machining operations, although these can be partially addressed via constrained stress relief during aging. Aging is usually accomplished between $495^{\circ} \mathrm{C}$ and $525^{\circ} \mathrm{C}$ for $8 \mathrm{~h}$ followed by an air cool, and it serves as a stress relief treatment. As suggested by the Mo-Eq value of 10 , the pseudobinary phase diagram in Fig. 2, and the TTT in Fig. 10, Ti-10V$2 \mathrm{Fe}-3 \mathrm{Al}$ may form both athermal and isothermal omega. The impacts of precursor omega on alpha precipitation and properties in $\mathrm{Ti}-10 \mathrm{~V}-2 \mathrm{Fe}-3 \mathrm{Al}$ have been considered previously, ${ }^{44,67,68}$ and it has been observed that the embrittling effects of omega particles can be minimized by beta grain size refinement. ${ }^{68}$ Interestingly, it has also been reported that strengthening through the precipitation of omega instead of alpha retards fatigue crack growth significantly, which was attributed to changes in slip character and reversibility. ${ }^{44}$

\section{Ti-15V-3Cr-3Al-3Sn}

Ti-15V-3Cr-3Al-3Sn was developed in the 1970s by TIMET and Lockheed under Air Force support as an economical titanium sheet alloy that could be

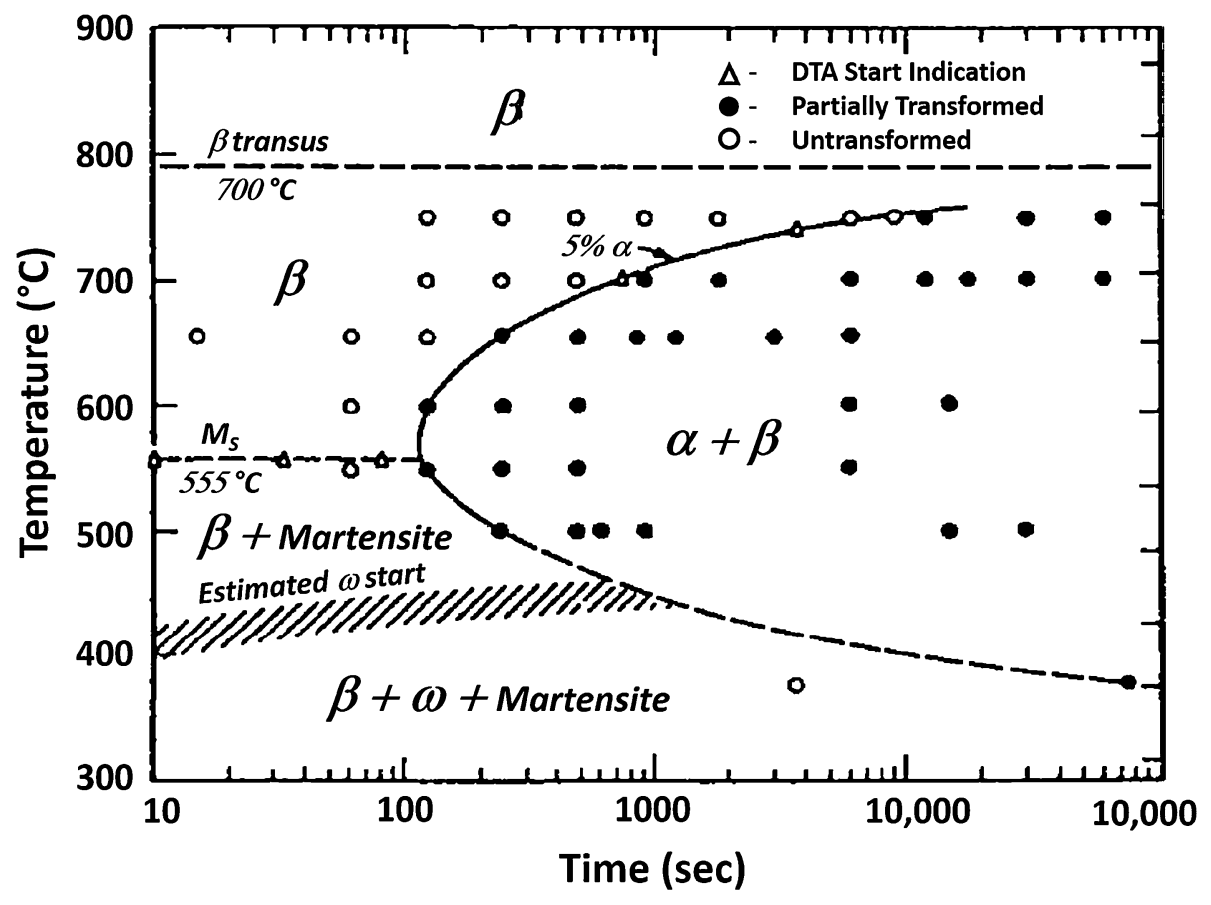

Fig. 10. TTT diagram for Ti-10-2-3. ${ }^{53}$ Test material was solution treated at $860^{\circ} \mathrm{C}\left(1580^{\circ} \mathrm{F}\right)$ for $240 \mathrm{~s}$. 


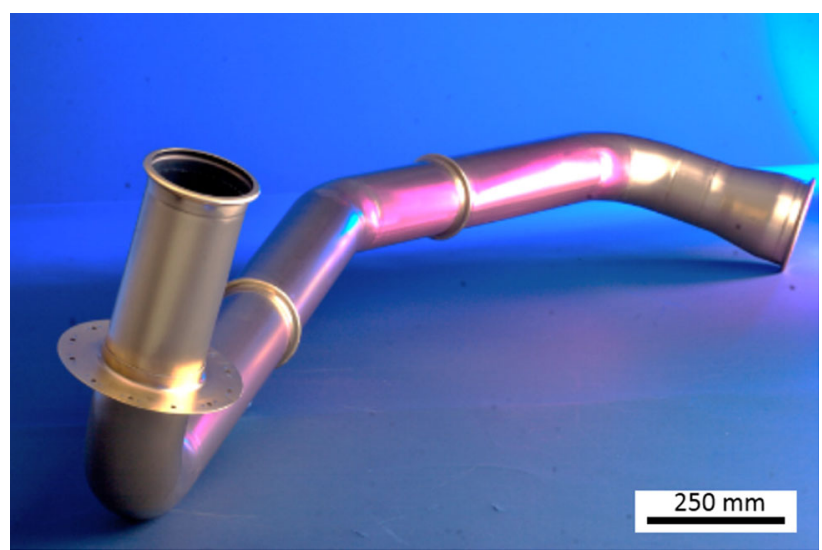

Fig. 11. Ti-15V-3Al-3Sn-3Cr welded environmental control system duct (photo courtesy of Exotic Metals, Kent, WA).

cold formed to reduce fabrication costs and enable repairs in the field. ${ }^{69}$ The chemistry was downselected from more than 60 compositions and contained the lowest chromium level of the competing options. ${ }^{70}$ The high degree of beta stabilization enables cold-rolled strips to be produced in the form of coil, providing long lengths and an economy of scale that avoids the labor-intensive pack-rolling operations attendant to alpha-beta alloys like Ti6Al4V. The first important application of Ti-15V$3 \mathrm{Al}-3 \mathrm{Sn}-3 \mathrm{Cr}$ was the aft nacelle structure of the Rockwell B-1B bomber, in which roughly 100 components (55 part numbers), both structural and nonstructural, were fabricated from sheet at a cost savings over hot-formed Ti6Al4V because of its excellent formability. ${ }^{71}$ The formability of Ti-15V-3Al3Sn-3Cr also permits ready fabrication of welded tubing, which is an important product form for commercial and military aerospace environmental control system ducting (Fig. 11). In the early 1990s, implementation of Ti-15V-3Al-3Sn-3Cr ducting on the Boeing 777 environmental control system saved approximately $63.5 \mathrm{~kg}$ (140 lbs) of airframe weight by replacing $\mathrm{CP} \mathrm{Ti}^{3,26}$ Other applications were described by Boyer. ${ }^{3}$

\section{Chemical Composition and Processing}

Compositional limits for Ti-15V-3Al-3Sn-3Cr are given in Table II. ${ }^{72}$ Ti-15V-3Al-3Sn-3Cr is effectively stabilized to a level just beyond that of Ti5553 (Fig. 3). By minimizing beta eutectoid alloying additions, this composition enables improved ingot processing and reduced segregation. Although heavier product forms are possible, based on the TTT diagram in Fig. $12,{ }^{73}$ the sensitivity of the aging response to the degree of cold work ${ }^{9,69}$ largely relegates $\mathrm{Ti}-15 \mathrm{~V}-3 \mathrm{Al}-3 \mathrm{Sn}-3 \mathrm{Cr}$ to sheet, strip, and foil products of relatively constant cross section (and accordantly small ranges of strain and cooling rate). Excellent weldability has enabled tubing and ducting to be important product forms, although attention must be paid to the degree of cold work

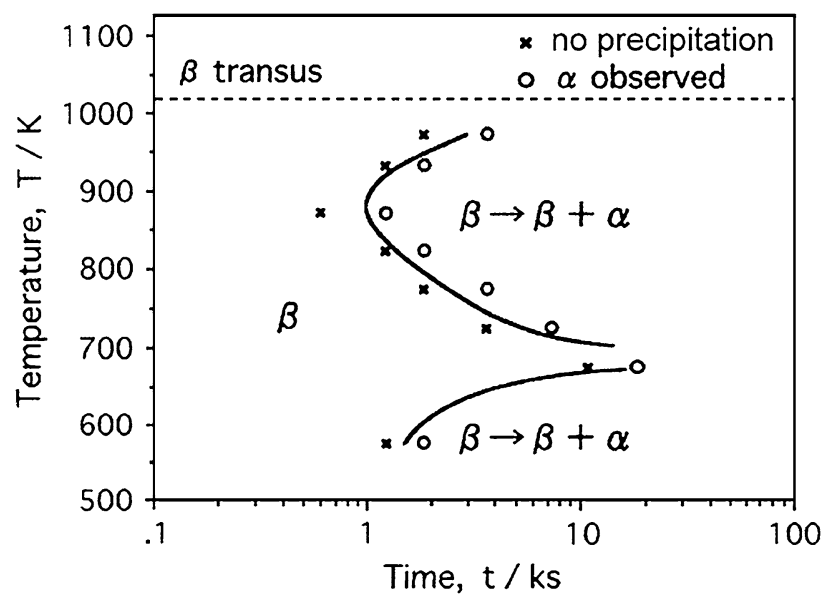

Fig. 12. TTT diagram for Ti-15V-3Al-3Sn-3Cr (Ref. 73).

imparted during tube bending and expansion operations to avoid significantly altering the aging response. $^{26}$

\section{Microstructure and Properties}

A typical solution-treated and aged light optical microstructure for Ti-15V-3Al-3Sn-3Cr is shown in Fig. 13. At commercial aging temperatures, the predominant nucleation site for alpha precipitation in $\mathrm{Ti}-15 \mathrm{~V}-3 \mathrm{Al}-3 \mathrm{Sn}-3 \mathrm{Cr}$ is dislocation substructures and associated slip bands, making the aging response highly correlated to thermomechanical processing. ${ }^{74}$ Below $400^{\circ} \mathrm{C}$, omega has been observed as a precursor phase, which has been suggested to create a more homogeneous dispersion of alpha, but it must be balanced against recovery processes. $^{73}$ Cold work increases tensile properties and accelerates the precipitation reaction. It has been determined that control of annealing and recrystallization is vital to property development, and these processes are sensitive to impurity levels that trace back to sponge purity. ${ }^{49,75}$ It has also been put forth that deformation reduces the amount of omega formed, which in turn diminishes alpha precipitation (although this may be compensated by the resulting dislocation substructure to some extent). As with other beta titanium alloys, a continuous layer of grain boundary alpha is not allowed due to low ductility effects. Other parameters affecting recrystallization include the heating rate to the solution treatment temperature, which affects the degree of annihilation of alpha nucleation sites.

The aging temperature has a linear effect on both strength and ductility, as illustrated in Fig. 14.

\section{Beta C (Ti-3Al-8V-6Cr-4Mo-4Zr)}

Ti-3Al-8V-6Cr-4Mo-4Zr (Beta C), is a metastable beta titanium alloy developed by RMI Titanium Company in the late 1960 s as a more robust alternative to Ti-13V-11Cr-3Al for aerospace applications. The alloy formulation was based on careful 


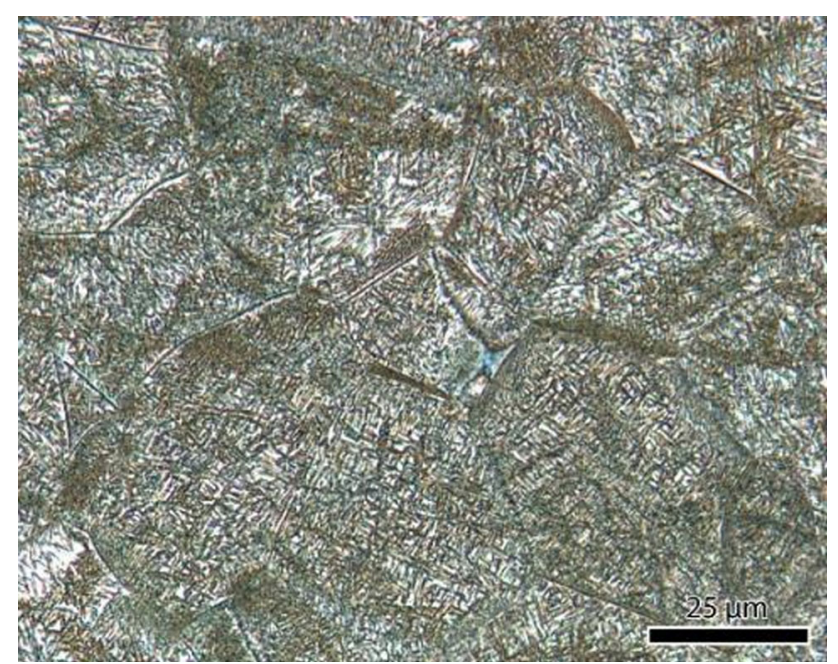

Fig. 13. Ti-15V-3Al-3Sn-3Cr tubing, STA condition, light optical photomicrograph, 1000 times magnification.

consideration of mechanical properties, cold and hot workability, density, raw material costs, and ease of ingot manufacture. ${ }^{20}$ The reduction of $\mathrm{Cr}$ content in Beta $\mathrm{C}$ from the high level in Ti-13V-11Cr-3Al allowed for a reduced segregation tendency, similar to the later Ti5553 development. In the early 1980s, it was recognized that Beta $\mathrm{C}$ also possessed superior corrosion resistance in reducing acids and hot chloride environments, which expanded the application base of Beta $\mathrm{C}$ to oil and gas industries. Beta $\mathrm{C}$ is appropriate for applications where very high strength, light weight, low modulus, and corrosion resistance are important. Particular applications of Beta $\mathrm{C}$ include aircraft springs, fasteners, and underground tubes and casing equipment for oil and gas wells. Due to the reduced modulus and density, Beta $\mathrm{C}$ springs can offer up to $70 \%$ weight savings over steel springs for aircraft applications, as well as improved corrosion resistance. ${ }^{17}$ An example Beta C spring is shown in Fig. 15.

Beta $\mathrm{C}$ is currently in production and the applications include aerospace springs, fasteners, and fittings; oil field drilling tools, production tubulars, accessories, wireline tools; and geothermal equipment. Production volumes are relatively low (much less than $1 \%$ of total titanium production) due to low volume applications. Similar to other beta alloys, barriers to growth for Beta $\mathrm{C}$ continue to be limited recycled material availability resulting in high alloy cost, special care requirements in melting and processing, and risk perception due to complexity of the alloy.

\section{Chemical Composition and Processing}

Compositional ranges permitted in Beta $\mathrm{C}$ are shown in Table II. ${ }^{76,77}$ Beta $\mathrm{C}$ is heavily beta stabilized, thereby allowing deep hardenability in heavy section sizes $>150 \mathrm{~mm}$ or 6 in. Although the inherent metallurgical characteristics of Beta $\mathrm{C}$ are improved compared with Ti-13V-11Cr-3Al, melting

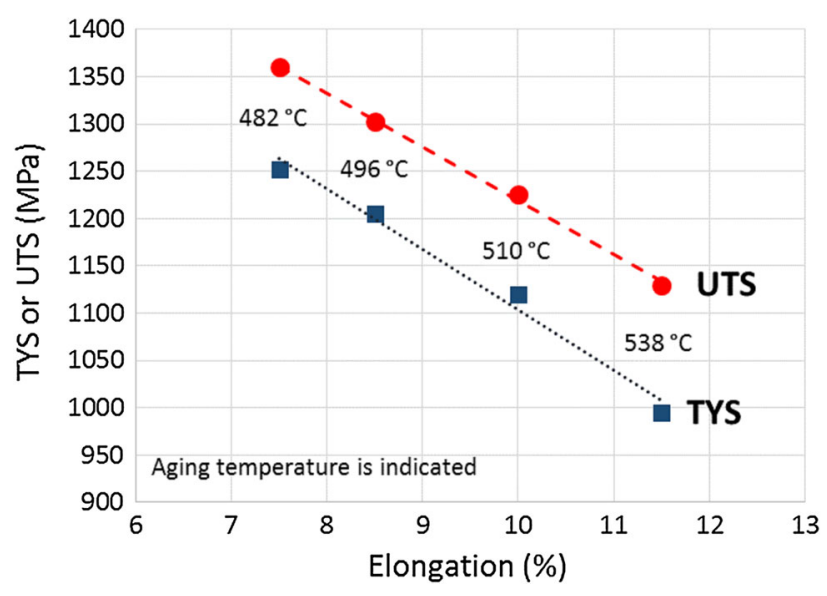

Fig. 14. Tensile ultimate and yield strength versus ductility for Ti$15 \mathrm{~V}-3 \mathrm{Al}-3 \mathrm{Sn}-3 \mathrm{Cr}$ strip as a function of aging at temperatures from $482-938^{\circ} \mathrm{C}\left(900-1000^{\circ} \mathrm{F}\right) .^{49}$ The aging temperature applied to each strength level is indicated in the diagram.

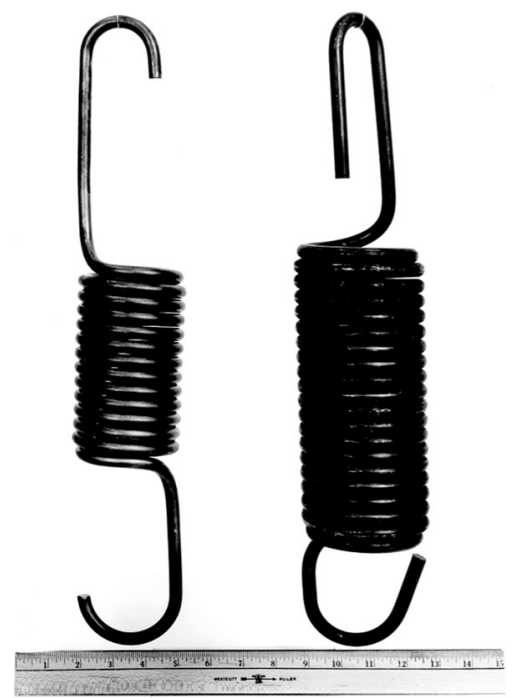

Fig. 15. Comparison of landing gear actuation springs of equivalent spring constant: left-Beta $C$ weighing $1.45 \mathrm{~kg}$ (3.2 lbs); right-17$4 \mathrm{PH}$ stainless steel weighing $4.35 \mathrm{~kg}(9.6 \mathrm{lbs})$.

processes must be designed to minimize as-cast segregation. It is melted by traditional VAR and plasma arc melting (PAM) methods and has been successfully single melted via PAM at a smaller than typical ingot diameters. ${ }^{76}$

Beta C can be processed by conventional hotworking methods such as forging, rolling, and extrusion. Hot working temperatures are typically above the beta transus $\left(1460^{\circ} \mathrm{F}\right.$ or $\left.795^{\circ} \mathrm{C}\right)$, and forgability is good at these temperatures. Beta $\mathrm{C}$ can also be readily cold worked. Cold reductions of $60-$ $70 \%$ are common. Cold drawing, bending, wrapping, and rolling are commonly used in the production of wire products, springs, and seamless tubing. Aerospace material specification (AMS) standards for Beta $\mathrm{C}$ products are shown in Table IV. 
Table IV. Beta C industry standard specifications for common product forms

\begin{tabular}{|c|c|c|}
\hline Standard & Product form & Typical application \\
\hline AMS 4957 & $\begin{array}{c}\text { Round bar and wire, solution heat treated and cold drawn, } \\
0.625 \text { in. and under nominal diameter }\end{array}$ & Coil springs \\
\hline AMS 4958 & $\begin{array}{c}\text { Bars and rounds, solution heat treated and centerless ground, } 1 \text { in. } \\
\text { and under nominal diameter }\end{array}$ & Coil springs \\
\hline AMS 6920 & Bars, forgings, and forging stock, solution heat treated & $\begin{array}{l}\text { High-stress and } \\
\text { stress-corrosion-resistance parts }\end{array}$ \\
\hline AMS 6921 & Bars, forgings, and forging stock, solution heat treated and aged & $\begin{array}{l}\text { High-stress and } \\
\text { stress-corrosion-resistance parts }\end{array}$ \\
\hline
\end{tabular}

Table V. Minimum mechanical properties of Beta C round bar and wire in the STA condition ${ }^{77}$

\begin{tabular}{|c|c|c|c|c|}
\hline Thickness (mm) & $0.2 \%$ TYS (MPa) & UTS (MPa) & $\% \mathrm{El}(\min )$ & $\%$ RA (min) \\
\hline Up to 4.75 & Not specified & $1310-1448$ & 10 & 20 \\
\hline $4.75-9.52$ & Not specified & $1276-1413$ & 10 & 20 \\
\hline $9.52-15.88$ & Not specified & $1241-1379$ & 8 & 20 \\
\hline
\end{tabular}

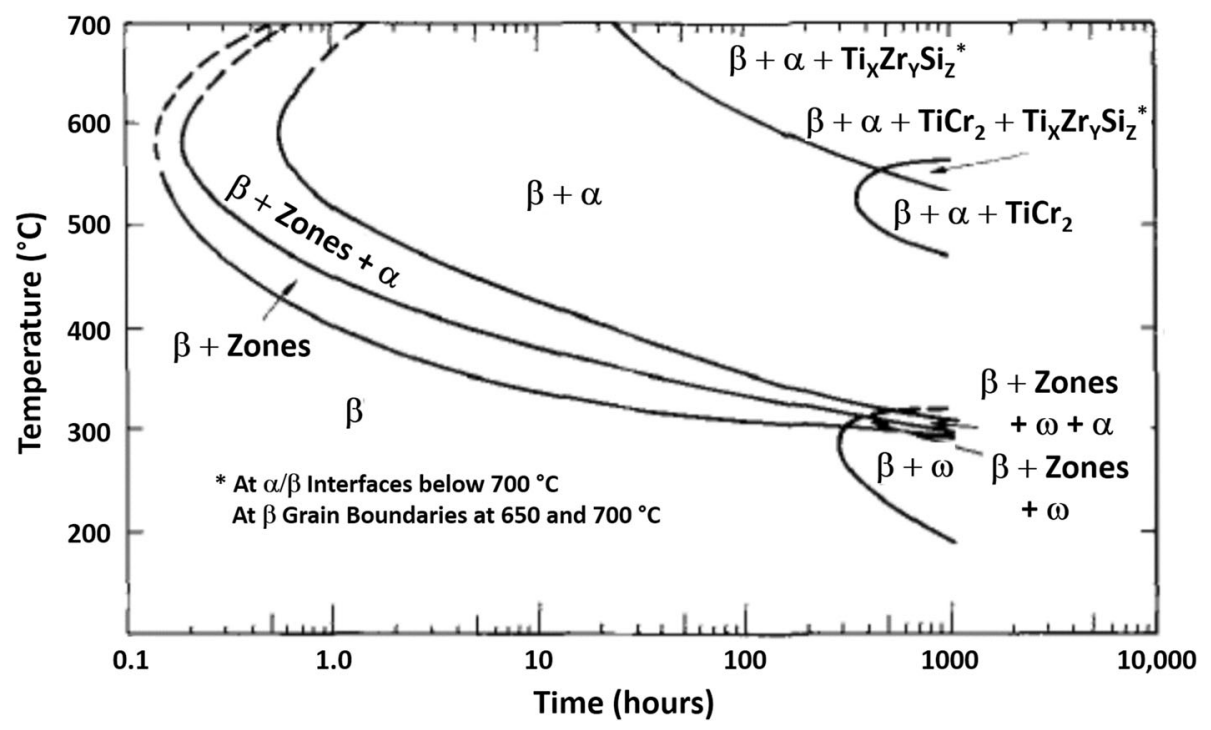

Fig. 16. TTT Diagram for solution-treated and air-quenched Beta C. ${ }^{54}$

\section{Microstructure and Mechanical Properties}

Beta $\mathrm{C}$ is solution treated in the range 1450$1700^{\circ} \mathrm{F}\left(790-925^{\circ} \mathrm{C}\right)$ for $30 \mathrm{~min}$ to $1 \mathrm{~h}$ followed by air cooling, forced air cooling, or water quenching depending on section size. The typical aging treatment cycle is $875-1150^{\circ} \mathrm{F}\left(470-620^{\circ} \mathrm{C}\right)$ for $4-12 \mathrm{~h}$ depending on the product form and desired final mechanical property combinations. Beta $\mathrm{C}$ can be used in either the solution treated (ST) or the solution treated plus aged (STA) conditions. Increases in strength on the order of $40 \%$ are obtained by precipitation strengthening, as noted in Table V. Cold work increases the strength of the alloy in the ST condition and accelerates the aging response. Beta $\mathrm{C}$ is stress relieved in the range $1300-1400^{\circ} \mathrm{F}$ for $10-60 \mathrm{~min}$.
Several phases are possible in Beta $\mathrm{C}$ due to the complexity of the chemistry and ability to form metastable phases. These can include: alpha (hcp), beta (bcc), beta prime $\left(\beta^{\prime}\right)$, omega $(\omega)$, titanium chromide $\left(\mathrm{TiCr}_{2}\right)$, and a silicide $\left((\mathrm{Ti}, \mathrm{Zr})_{5} \mathrm{Si}_{3}\right){ }^{20}$ Commercial aging temperatures have been developed to be sufficiently high to avoid omega and aging times sufficiently short to avoid $\mathrm{TiCr}_{2}$, which can be embrittling. The enriched beta phase has been suggested to decompose by a phase separation reaction into solute-rich and solute-lean beta: $\beta_{\mathrm{ss}} \rightarrow \beta+\beta^{\prime}$ (Ref. 78) and by more complex reactions. ${ }^{54}$ Either way, precipitation of $\alpha$ is sluggish (see the TTT in Fig. $16^{54}$ ), and the aging response is sensitive to the degree of prior mechanical work 


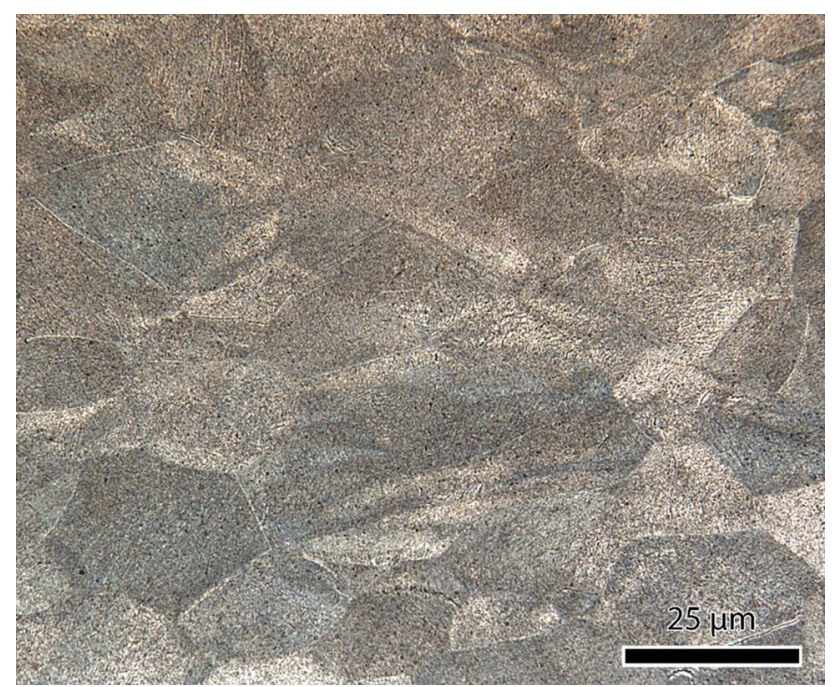

Fig. 17. Light optical micrograph of Beta $C$ in the STA condition. Precipitation of fine alpha in beta grains after aging is indicated by the general darkening of the matrix beta phase (Kroll's etch).

that must be set by fixed practice. Thus, thermomechanical processing schedules must be carefully designed to allow subsequent uniform aging in thick section products. One way this can be alleviated is by duplex aging, where initial aging in the 420 $460^{\circ} \mathrm{C}\left(788-860^{\circ} \mathrm{F}\right)$ range is followed by aging at higher temperatures to achieve the desired strength level. ${ }^{28}$ The initial age allows the solute-lean metastable $\beta^{\prime}$ phase to develop via a phase-separation reaction. During the second step of the duplex aging process, $\alpha$-phase nucleates on the leaner $\beta^{\prime}$, resulting in a more uniform $\alpha$ distribution. ${ }^{76}$

In the solution annealed condition, the microstructure of Beta C consists of metastable beta phase, which is readily retained at common section sizes by water quenching or air cooling. Beta grain size varies depending on section size and thermomechanical processing history. Fine alpha platelets precipitate during aging, the number density of which trend with the degree of local plastic strain, and a very thin layer of grain boundary alpha can sometimes occur. A light optical photomicrograph of the microstructure of Beta $\mathrm{C}$ bar in the aged condition is shown in Fig. 17.

Depending on the product form, orientation, and final strength level after STA heat treatment, the fracture toughness of Beta-C $\left(\mathrm{K}_{\mathrm{Ic}}\right)$ ranges from 49 to $88 \mathrm{MPa} \sqrt{\mathrm{m}}(45-80 \mathrm{ksi} \sqrt{\mathrm{in}})$.

\section{Beta 21S (Ti-15Mo-3Al-3Nb-0.2Si)}

While beta titanium alloys exhibit a number of attractive characteristics, one of the challenges in this class has been elevated temperature properties. Applications requiring high temperature strength, creep, and oxidation are largely left to the near-alpha alloys. However, Beta 21S (Ti-15Mo-3Al-3Nb$0.2 \mathrm{Si}$ ) is a bit of an anomaly in this regard. Beta $21 \mathrm{~S}$

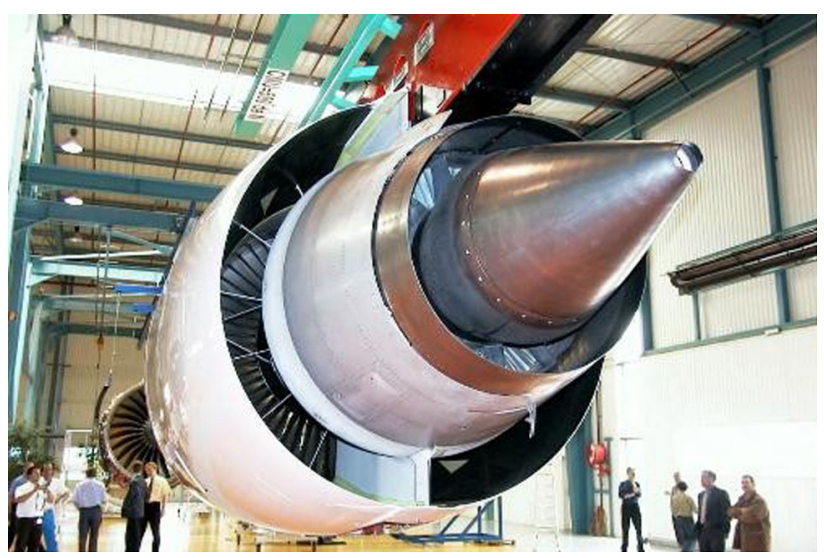

Fig. 18. Beta $21 \mathrm{~S}$ plug-and-nozzle assemblies for the trent 500 engine on the Airbus A340-500/600 49 .

is a metastable beta titanium alloy developed by TIMET in 1988 to satisfy the need for a foil-producible titanium alloy with good high-temperature behavior. The initial target application was for metal matrix composites on the National Aerospace Plane program. ${ }^{48}$ Over the ensuing decades, the alloy's unique combination of producibility, high ambient strength, good elevated temperature properties, and extraordinary environmental degradation resistance has proven useful for both civil and military aeroengine exhaust components. For example, the plug-and-nozzle assemblies of the Rolls Royce Trent 400 engine on the Airbus A340 (Fig. 18) and the Boeing 777 are long-standing applications. Using Beta 21S instead of Inconel 625 eliminated approximately $164 \mathrm{~kg}$ (360 lbs) on the Boeing 777 aircraft. $^{26}$ New applications are in development, such as for the Boeing 737MAX, in which the thrust reverser inner wall is being converted to titanium to allow for an increased fan diameter for the aircraft's CFM Leap-1B engines without a proportional increase in the size of the nacelle, further improving projected thrust levels. This application also allowed for reduced weight and maintenance costs. ${ }^{79}$

Among the alloy's unique properties is a high resistance to attack by commercial aircraft hydraulic fluids over a wide range of temperatures. ${ }^{22}$ The mechanism(s) behind this resistance have yet to be elucidated but seem to correspond to good resistance to hydrogen uptake as well. It has the highest creep resistance of any metastable beta titanium alloy, although still less resistant to creep than commercial, high-temperature near-alpha alloys.

\section{Chemical Composition and Processing}

The typical chemical composition range for Beta 21S is shown in Table II. ${ }^{80}$ Versions of the alloy are also available with palladium additions (when extremely high stress corrosion resistance is required) and without aluminum (for orthopedic implant applications). ${ }^{48}$ Although vanadium is the most com- 


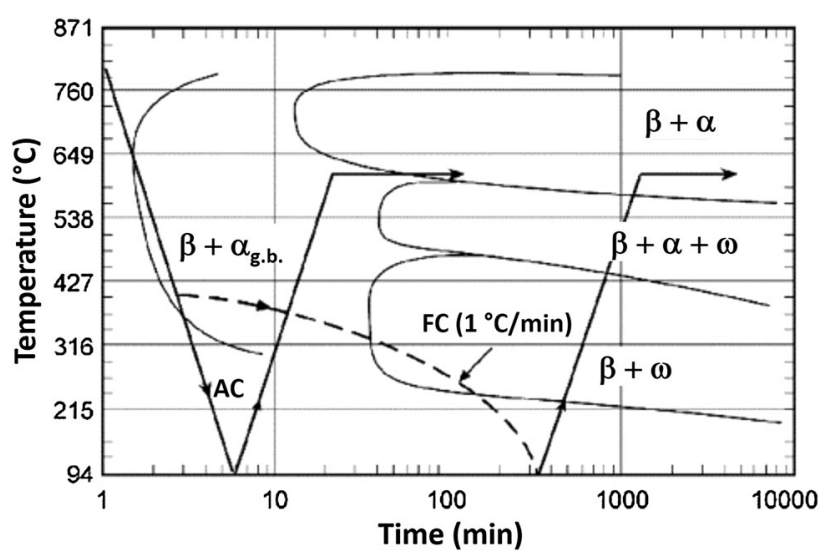

Fig. 19. TTT diagram for air-quenched beta $21 \mathrm{~S}^{84,85}$

mon beta stabilizer for beta titanium alloys, it was not considered in the formulation of the alloy due to its detrimental effect on oxidation resistance. Evaluations of the effects of ternary additions on cold rollability and oxidation resistance to either TiMo or Ti-Cr binary bases indicated that the Ti-Mo system held the most potential, with the oxidation resistance optimized at $15 \mathrm{wt} . \%$ Mo for $1500^{\circ} \mathrm{F} / 48 \mathrm{~h}$ exposures in air. Further chemistry optimization resulted in the Ti-15Mo-2.7Nb-3Al-0.2Si-0.15O2 target. The alloy was designated "Beta $21 \mathrm{~S}$ " since it is a beta alloy, containing nominally $21 \mathrm{wt} . \%$ of alloying additions, including silicon (S). ${ }^{21}$

Beta 21S is currently produced by triple VAR to promote dissolution of the substantial refractory metal content. After forging to slab and rolling to approximately $4 \mathrm{~mm}$ thickness hot band, further reductions may be accomplished by cold rolling, up to $75 \%$, without annealing. ${ }^{21}$

Beta $21 \mathrm{~S}$ is usually supplied in the solution heattreated condition. In this condition, the alloy has a single-phase (beta) structure and, hence, can be readily cold formed. For maximum cold formability and subsequent uniformity of properties in the aged condition, the solution-treated material should contain at least $80 \%$ recrystallized beta grains with an average grain size finer than ASTM 4. After cold forming, the alloy can be aged to the desired strength level. Cold reductions greater than $80 \%$ are possible in most compressive operations, including rolling, spinning, and swaging. Like other metastable beta titanium alloys in the solution heattreated condition, Beta $21 \mathrm{~S}$ does not work harden quickly. Therefore, large cold deformation is possible when strains are uniform, such as in hydrostatic forming. Surface contamination (alpha case), when present, must always be removed prior to cold forming to avoid crack initiation.

Beta $21 \mathrm{~S}$ is solution heat treated at $816-899^{\circ} \mathrm{C}$ $\left(1500-1650^{\circ} \mathrm{F}\right)$ for $3-30 \mathrm{~min}$. Longer super-transus exposures can result in excessive beta grain growth. For service temperatures $<427^{\circ} \mathrm{C}\left(800^{\circ} \mathrm{F}\right)$ that require higher strength, Beta $21 \mathrm{~S}$ is usually aged at $593^{\circ} \mathrm{C}\left(1100^{\circ} \mathrm{F}\right)$ for $8 \mathrm{~h}$. For elevated temperature applications, a duplex age of $690^{\circ} \mathrm{C}\left(1275^{\circ} \mathrm{F}\right)$ for $8 \mathrm{~h}$ plus $649^{\circ} \mathrm{C}\left(1200^{\circ} \mathrm{F}\right)$ for $8 \mathrm{~h}$ is used, which provides an added degree of thermal stability. Thermal stability can be a limiting factor, as $21 \mathrm{~S}$ should not be put in service at elevated temperatures [above $\left.204^{\circ} \mathrm{C}\left(400^{\circ} \mathrm{F}\right)\right]$ in the solution-treated condition. Such exposures can result in particularly fine alpha precipitation, exhibiting very high strength and low ductility. ${ }^{21}$ Furthermore, extended air exposures of thin products, less than $1 \mathrm{~mm}$, to temperatures above $900^{\circ} \mathrm{C}$ may also exhibit unacceptably low ductility values due to surface contamination from interstitial oxygen. ${ }^{81}$

\section{Microstructure and Properties}

Microstructure development in Beta 21S is similar to other beta titanium alloys and depends on obtaining a mostly recrystallized beta microstructure prior to air cooling from the beta phase field and subsequent alpha precipitation. A refined beta grain size is important for ductility and formability. ${ }^{10,82}$ A sufficiently high cooling rate may avoid grain boundary nucleation of alpha, but in general, grain boundary alpha cannot be avoided (Fig. 19). Alpha precipitation depends on several factors: cooling rate from solution treatment, heating rate to the aging temperature, aging temperature(s), and degree of retained cold work. The more straightforward single stage aging at $593^{\circ} \mathrm{C}\left(1100^{\circ} \mathrm{F}\right)$ for $8 \mathrm{~h}$ can result in direct sympathetic nucleation of alpha on grain boundary platelets if cooling and heating rates are adequately fast. If the solution treatment cooling rate is substantially slower, such as during furnace cooling or air cooling of large sections or structures, causing the material to pass through the $(\beta+\omega)$ and $(\beta+\alpha+\omega)$ fields, then more homogenous distribution of nucleation sites for alpha will result. $^{10}$

The duplex aged condition (also termed STOA), more common for elevated temperature applications, operates solidly within the $\beta \rightarrow(\alpha+\beta) \mathrm{C}$ curve of Fig. 19 but is likewise subject to changes in alpha distribution due to omega nucleation at slow cooling and heating rates. It involves two 8-h aging steps, the first at $690^{\circ} \mathrm{C}\left(1275^{\circ} \mathrm{F}\right)$ for $8 \mathrm{~h}$ and second at $649^{\circ} \mathrm{C}\left(1200^{\circ} \mathrm{F}\right)$ for another $8 \mathrm{~h}$. The first treatment precipitates $20-30$ vol.\% of coarse primary alpha and enriches the beta phase in $\mathrm{Mo}$ and $\mathrm{Nb}$. As a result, the matrix becomes more stable and the driving force for subsequent aging decreases. ${ }^{55,83}$ The second aging step increases strength via precipitation of finer alpha phase, albeit to lower levels than single stage aging, as noted in Table VI. A typical duplex aged microstructure is provided in Fig. 20. This photomicrograph shows visible beta grain boundaries highlighted by lighter etching alpha platelets that have previously nucleated and coarsened prior to the intragranular precipitation of the fine alpha which has darkened the grain inte- 
Table VI. Typical Minimum tensile properties of beta $21 \mathrm{~S}$ sheet, through $4.75 \mathrm{~mm}(0.187 \mathrm{in}$.

\begin{tabular}{|c|c|c|c|c|c|}
\hline \multirow{2}{*}{ Condition } & \multicolumn{2}{|c|}{$\begin{array}{c}\text { Ultimate tensile } \\
\text { strength }\end{array}$} & \multicolumn{2}{|c|}{$0.2 \%$ yield strength } & \multirow{2}{*}{$\begin{array}{c}\text { Elongatior } \\
\%\end{array}$} \\
\hline & ksi & MPa & ksi & MPa & \\
\hline Single age & 150 & 1034 & 140 & 965 & 6 \\
\hline Duplex age & 125 & 862 & 115 & 793 & 10 \\
\hline
\end{tabular}

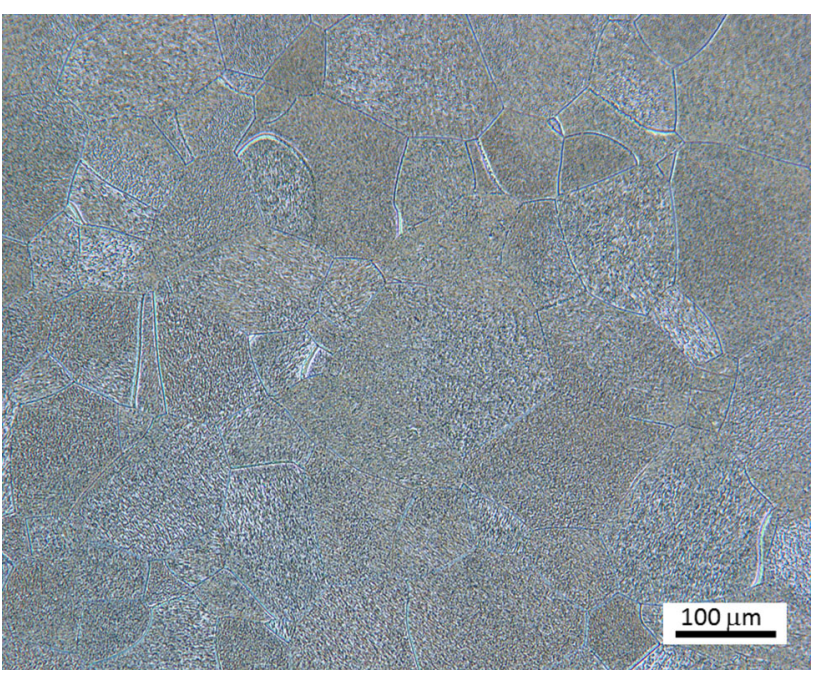

Fig. 20. Light optical photomicrograph of beta $21 \mathrm{~S}$ in the duplex aged condition (Kroll's etch).

riors. $\mathrm{Ti}_{5} \mathrm{Si}_{3}$ silicides have also been reported in Beta $21 \mathrm{~S},{ }^{83}$ although it is very fine and not visible by light optical methods.

\section{Ti-5Al-5Mo-5V-3Cr}

Ti-5Al-5V-5Mo-3Cr-0.5Fe (Ti-5553) alloy was developed in the late 1990s by VSMPO to provide processability and performance improvements (discussed below) over the established alloy Ti-10V-2Fe$3 \mathrm{Al} .{ }^{24} \mathrm{VT}-22$, nominally Ti5Al5V5Mo1Cr1Fe, was taken as the basis for Ti-5553 and is widely used in landing gear, load-bearing fuselage components, and high-lift devices of Russian wide-body aircraft. Ti-5553 comprises 5-7\% of serial production in Russia and is used for the manufacture of hand and die forgings for both airframe and landing gear applications, such as for the Boeing 787 (Fig. 21). ${ }^{86} \mathrm{~A}$ modification of Ti-5553 containing 1 wt.\% $\mathrm{Zr}$ (Ti55531) is marketed in Europe and is reportedly flying on the Airbus A380. ${ }^{87}$

\section{Chemical Composition and Processing}

Ti-5553 was formulated by increasing the $\mathrm{Cr}$ content and decreasing the Fe relative to VT-22, producing an alloy with more uniform macrostructure and microstructure, and improved hardenability relative to both VT-22 and Ti10-2-3. Nominal compositional limits are shown in Table II, although at present, there is no general industry

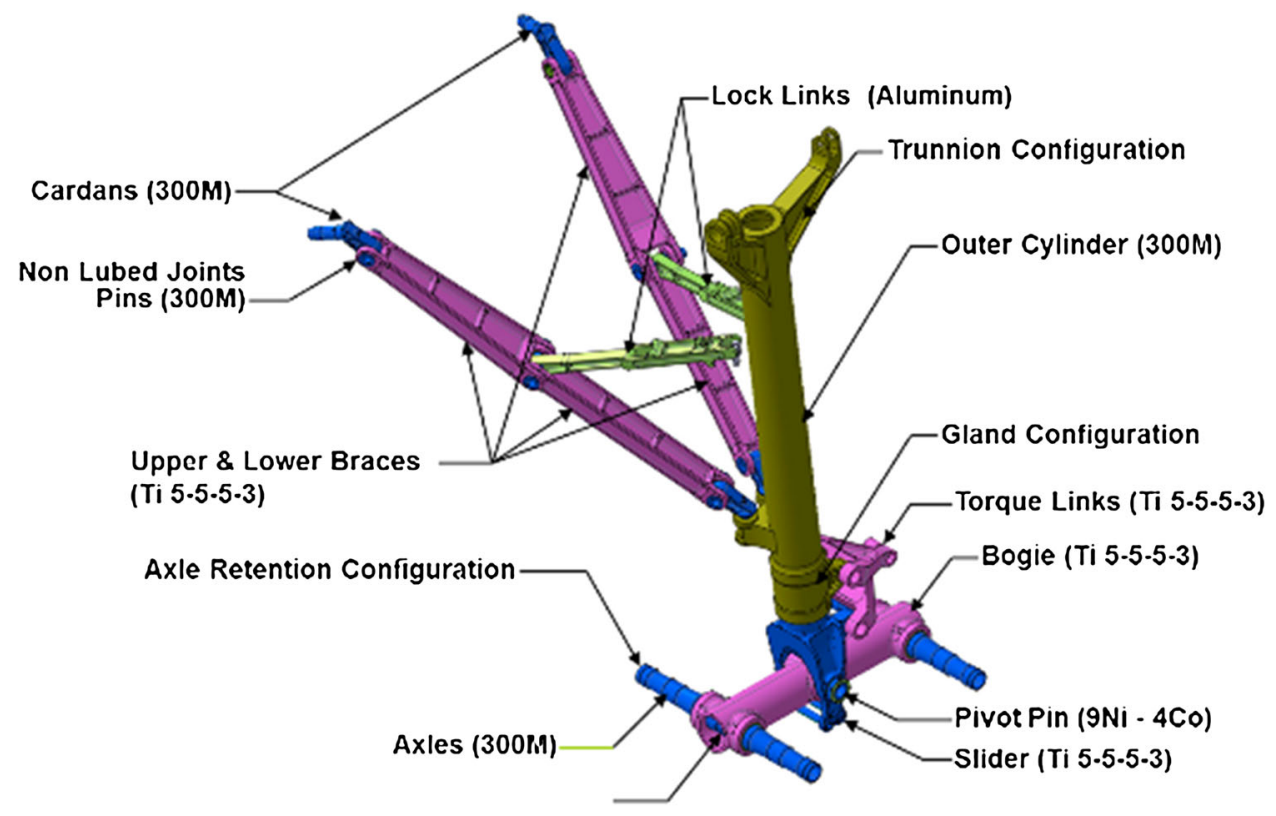

Fig. 21. 787 Main landing gear, illustrating several applications of Ti-5553 in the STA condition. ${ }^{86}$ 


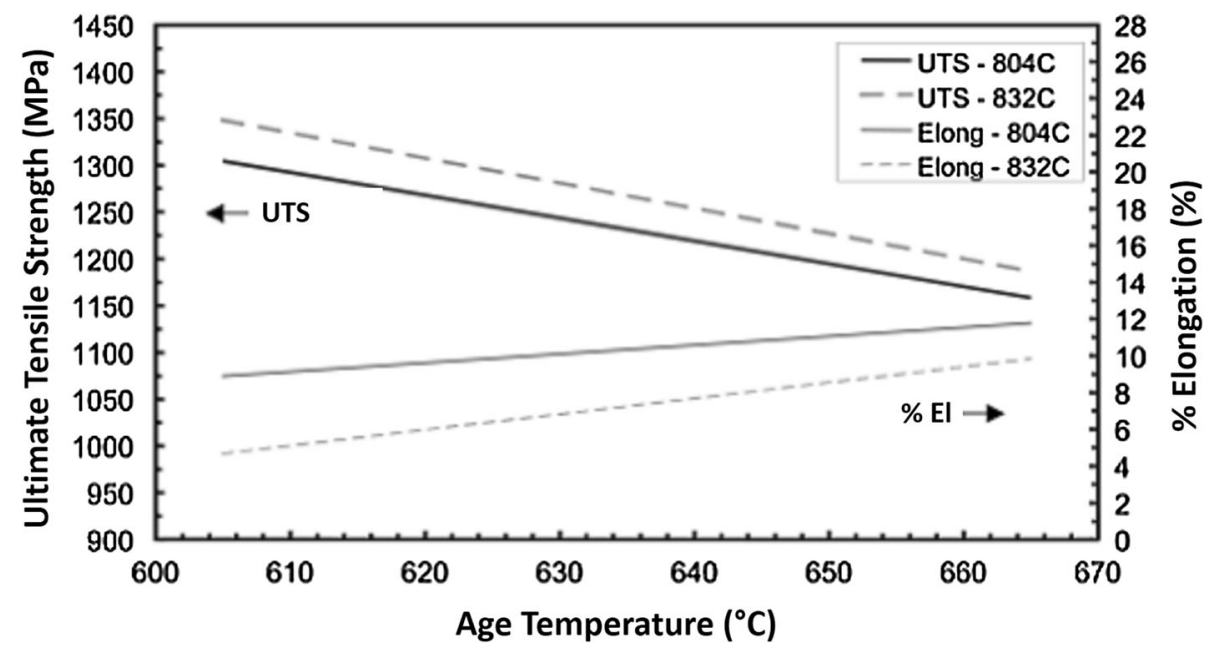

Fig. 22. Ultimate tensile strength (UTS) and elongation versus aging temperature $(8 \mathrm{~h})$ for $7 \mathrm{in}(178 \mathrm{~mm})$ diameter $\times 3.5 \mathrm{in}(89 \mathrm{~mm})$ long Ti5553 billet, solution treated at either $1480^{\circ} \mathrm{F}\left(804^{\circ} \mathrm{C}\right)$ or $1530^{\circ} \mathrm{F}\left(832^{\circ} \mathrm{C}\right) .^{47}$

specification for the production of Ti-5553 and manufacture is controlled by proprietary company standards. With the iron content limited to $0.5 \mathrm{wt} . \%$, the alloy is thus less prone to segregation. This allows ingot to be produced at a higher amperage and melt rate, which results in a significant reduction in process cycle time. Ingot homogenization is not required, improving yield. Primary billet conversion is accomplished mostly by alpha/beta work. ${ }^{8}$

An air cool provides sufficient quench rates from the solution treatment, for sections less than $150 \mathrm{~mm}$, and it provides higher ultimate strength than VT22 or Ti-10V-2Fe-3Al alloys on aging. The CCT diagram for alpha-beta solution treated Ti5553 ${ }^{56}$ suggests it is possible to retain $100 \% \beta$ phase via cooling at rates as low as $0.25^{\circ} \mathrm{C} / \mathrm{s} .{ }^{56} \mathrm{This}$ has been supported by other analyses ${ }^{88}$ in which it was demonstrated that both water quenching and air cooling produce microstructures without grain boundary alpha, which assists in maintaining good ductility in aged structures. Furthermore, Ti-5553 displays a shallower beta approach curve than $\mathrm{Ti}-$ 10-2-3, which allows a wider processing window for thermomechanical processing and heat treatment. Depending on chemical composition, the beta transus temperature may vary between $820^{\circ} \mathrm{C}$ and $880^{\circ} \mathrm{C}$. Typical heat treatments may be performed under the following conditions:

1. Solution treatment: Solution treatment at beta transus temperature minus $20-60^{\circ} \mathrm{C}$, soaking for $1 \mathrm{~h}$ min., air cooling. This condition is characterized by high ductility and low flow strength.

2. Solution Treatment and Age (STA):

2.1 Standard STA conditions. Solution heat treatment at beta transus temperature minus 20$60^{\circ} \mathrm{C}$, soaking for $1 \mathrm{~h}$ min., air cooling. Followed by ageing at $550-650^{\circ} \mathrm{C}$, for $8 \mathrm{~h}$ minimum.
2.2 Modified STA. Solution heat treatment is performed in two stages: the first stage-at beta transus temperature minus $20-60^{\circ} \mathrm{C}$, air cooling to ambient temperature or cooling with furnace to the second stage temperature. The second stage of solution heat treatment includes heating to $720-790^{\circ} \mathrm{C}$, soaking for $1-3 \mathrm{~h}$, air cooling. Compared to standard STA, these conditions provide a higher level of ductility.

3. Beta Annealed, Slow Cooled, and Aged (BASCA): Heating to the temperature of $20-60^{\circ} \mathrm{C}$ above beta transus temperature, soaking for $1 \mathrm{~h} \mathrm{min.,}$ cooling at controlled cooling rate to $650-800^{\circ} \mathrm{C}$, soaking for $1 \mathrm{~h}$ min., air cooling. ${ }^{42}$

4. Stress relief annealing: Heating to $650-750^{\circ} \mathrm{C}$, soaking for $4 \mathrm{~h}$ min., air cooling.

\section{Microstructure and Properties}

Depending on thermomechanical processing, various microstructures and $\alpha / \beta$ phase balances can be achieved in Ti5553. The tensile property dependence on aging has been reported by Fanning ${ }^{47}$ and is presented in Fig. 22. Low-temperature aging (below $500^{\circ} \mathrm{C}$ ) can result in omega phase (or pseudospinodal-separated beta phase ${ }^{89}$ ) that can significantly affect subsequent secondary alpha distributions and the strength/ductility balance. Fully aged microstructures attain roughly equal proportions of alpha and beta phases. ${ }^{58}$ Typical minimum room-temperature mechanical properties in three common conditions are given in Table VII.

Typical microstructures are shown in Fig. 23 for two different production conditions:

1. STA: This conditions consists of $10-20 \mathrm{vol} . \%$ globular primary alpha in a matrix of decomposed beta phase. The scale of the aged beta is quite fine and the individual alpha precipitates 
Table VII. Minimum mechanical properties of Ti5553 for section sizes up to $150 \mathrm{~mm}$

\begin{tabular}{|c|c|c|c|c|c|}
\hline $\begin{array}{l}\text { Heat-treatment } \\
\text { conditions } \\
\end{array}$ & $\begin{array}{c}\text { Tensile yield } \\
\text { strength (MPa) } \\
\end{array}$ & $\begin{array}{l}\text { Ultimate tensile } \\
\text { strength (MPa) } \\
\end{array}$ & Elongation (\%) & $\begin{array}{l}\text { Reduction } \\
\text { of area }(\%) \\
\end{array}$ & $\underline{\operatorname{KIc}\left(\mathbf{M P a} \sqrt{ }{ }_{\mathrm{m}}\right)}$ \\
\hline $\mathrm{ST}$ & 800 & 880 & 15 & 50 & \\
\hline STA & 1170 & 1240 & 4 & 10 & 33 \\
\hline BASCA & 965 & 1080 & 6 & - & 65 \\
\hline
\end{tabular}
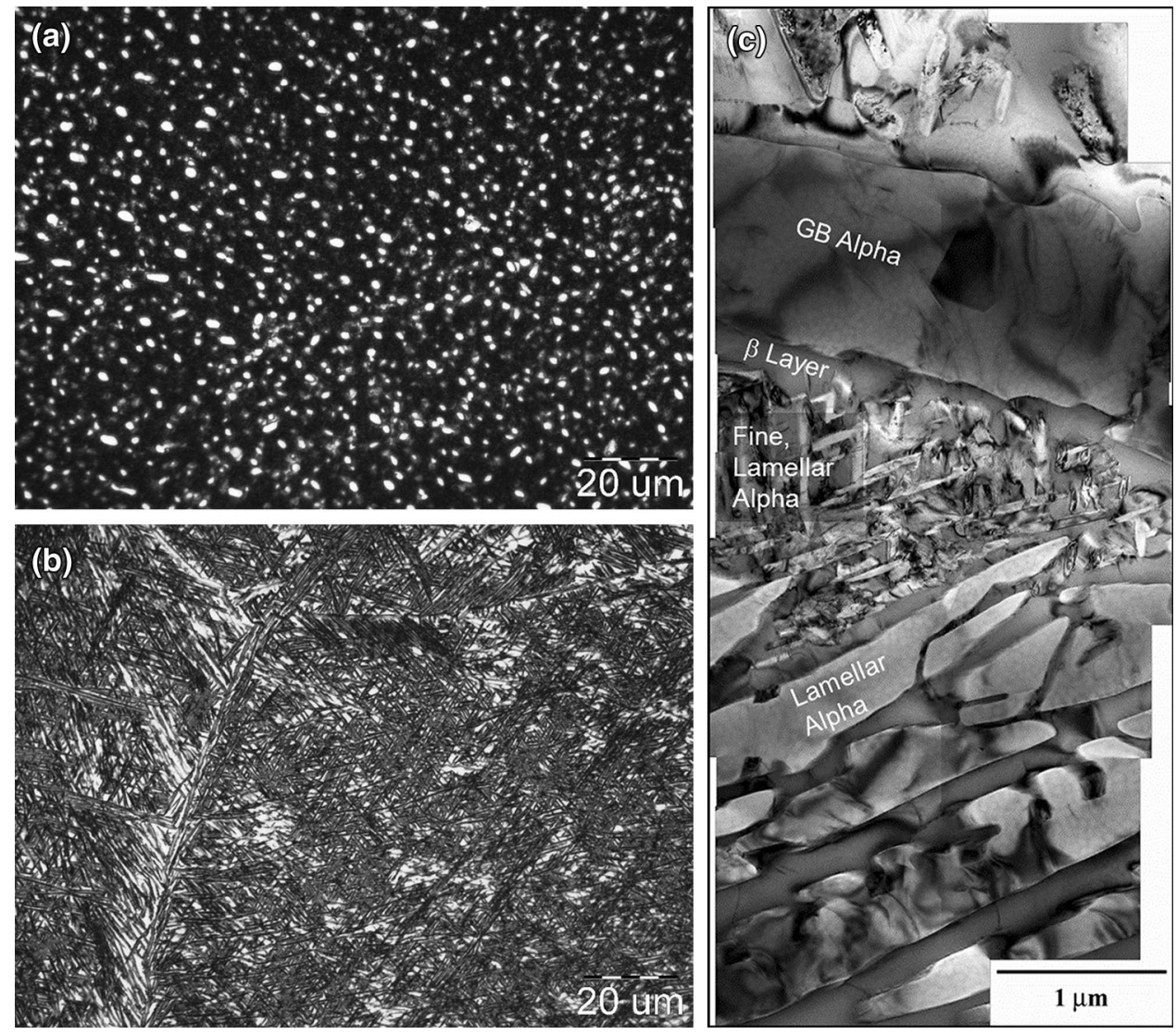

Fig. 23. Typical microstructures of Ti5553 in STA and BASCA conditions: (a) Light optical in the STA condition showing globular primary alpha (light) and dark-etching aged beta matrix, (b) Light optical in the BASCA condition showing coarse alpha platelets and minor amounts of retained beta (light), and (c) TEMBF image of the BASCA condition ${ }^{56}$ illustrating the different scales of coarse and fine lamellar alpha that allow an optimal combination of strength and toughness.

are generally not visible by optical microscopy. It is characterized by high strength and good fatigue behavior.

2. BASCA: This heat treatment results in a high volume fraction of lamellar alpha, which results from controlled cooling from beta-field temperatures. It is characterized by fracture toughness values double that of the STA condition $(\mathrm{KIc}>65 \mathrm{MPa} \sqrt{\mathrm{m}})$ and intermediate strength properties.

\section{Ti-35V-15Cr (Alloy C)}

In the mid-1980s, a need was identified for a noncombustible titanium alloy to support the exhaust nozzle design for the Pratt \& Whitney F119 engine on the F-22 Raptor. ${ }^{90,91}$ Under the anticipated service conditions, conventional high-temperature titanium alloys would be susceptible to sustained combustion and excessive temperatures and stresses. To avoid adding substantial weight via nickel-base superalloys, Pratt and Whitney embarked on a rapid alloy development program to mature an alloy based on the Ti-V-Cr ternary, which would satisfy these requirements, with a focus on improved combustion resistance. Considerable screening resulted in a composition centered on 35 wt. $\% \mathrm{~V}$ and $15 \mathrm{wt} . \% \mathrm{Cr},{ }^{92}$ which is rather unique in that it is the only production titanium-base system that is essentially a stable beta alloy. Processes 
for producing the alloy were developed and scaled by Teledyne Wah Chang Albany (now ATI Specialty Alloys and Components), and the alloy was considered mature after only 5 years of development. ${ }^{90}$ Despite a limited market, production applications have persisted. ${ }^{23}$

\section{Chemical Composition and Processing}

Alloy $\mathrm{C}$ is considered a stable beta alloy because quenching is not required to retain predominant beta phase, and significant alpha precipitation does not occur upon aging. This finding is consistent with the high Mo-Eq value of 47.5 in Fig. 3 and previous assessments. ${ }^{4,5}$ However, the target Ti35V15Cr composition apparently coincides with a liquidus trough in the ternary phase diagram. Furthermore, at least $11-13 \mathrm{wt} . \% \mathrm{Cr}$ is apparently required to impart burn resistance in this system, via improvement in oxidation resistance and a depressed melting point that assists in retarding sustained combustion by absorbing energy to the heat of fusion. ${ }^{92,93}$ Metallurgically, vanadium serves as the major beta phase stabilizer and solid-solution strengthener along with chromium. Carbon has a very low solubility and forms carbonitrides. ${ }^{94}$

Modifications to this base ternary have been evaluated for improved mechanical property performance, principally by adding silicon and/or carbon. ${ }^{95}$ To date, Alloy $\mathrm{C}$ may only be procured to proprietary specifications and no industry specifications exist to define working composition ranges and processing parameters. Similar burn-resistant alloys, containing deliberate carbon and/or aluminum additions, have been investigated and developed in the United Kingdom and China. ${ }^{94,96-98}$

Considerable effort went into maturing ingot casting procedures so as to ensure complete melting and mixing of $\mathrm{Cr}$ and $\mathrm{V}, 99$ and it seems that conventional arc and hearth methods may be applied to ingot production, provided the proper Ti-V master alloy is incorporated.$^{90,99}$ Thermomechanical processing routes have been devised to produce billet, sheet, foil, and extrusions, and welding parameters have likewise been developed for gas tungsten arc and electron beam methods. ${ }^{100}$

\section{Microstructure and Properties}

Microstructure development in Alloy $\mathrm{C}$ is not well publicized, but the microstructure essentially consists of recrystallized equiaxed beta phase with minor volume fractions of titanium carbides (depending on carbon content), $\mathrm{TiCr}_{2}$, and alpha phase, as shown in Fig. $24 .^{90,92,100}$ Based on the ternary equilibria, $\mathrm{TiCr}_{2}$ is expected to precipitate within the alpha phase. ${ }^{94}$

One of the most important properties of Alloy $\mathrm{C}$ is burn resistance, although the definition of burn resistance is a significant function of the type of test and the test parameters. ${ }^{97,98}$ Figure 25 compares the burn resistance of Alloy $\mathrm{C}$ to $\mathrm{Ti6Al4V}$ on a

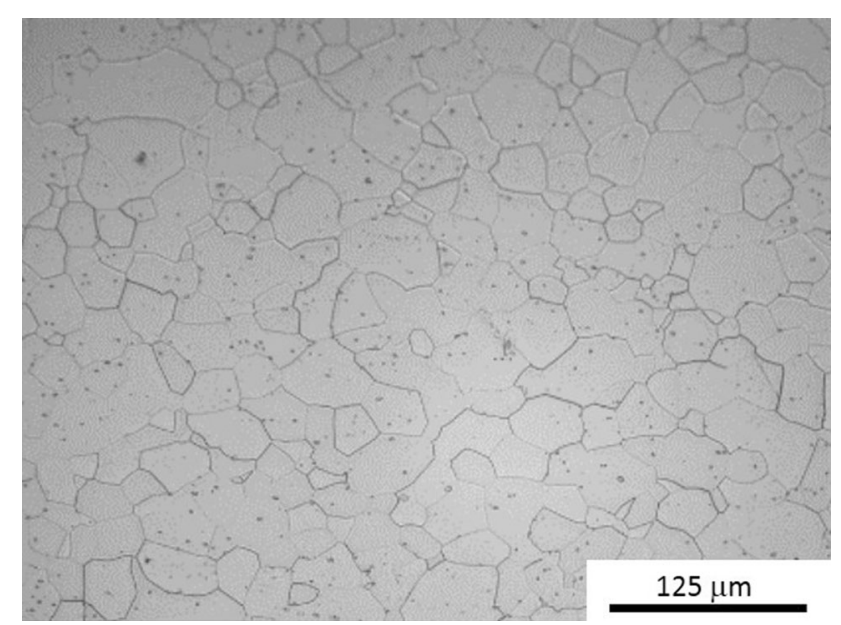

Fig. 24. Light optical photomicrograph of Alloy C. The minor, dark phase(s) may be alpha, $\mathrm{TiCr}_{2}$ or carbides.

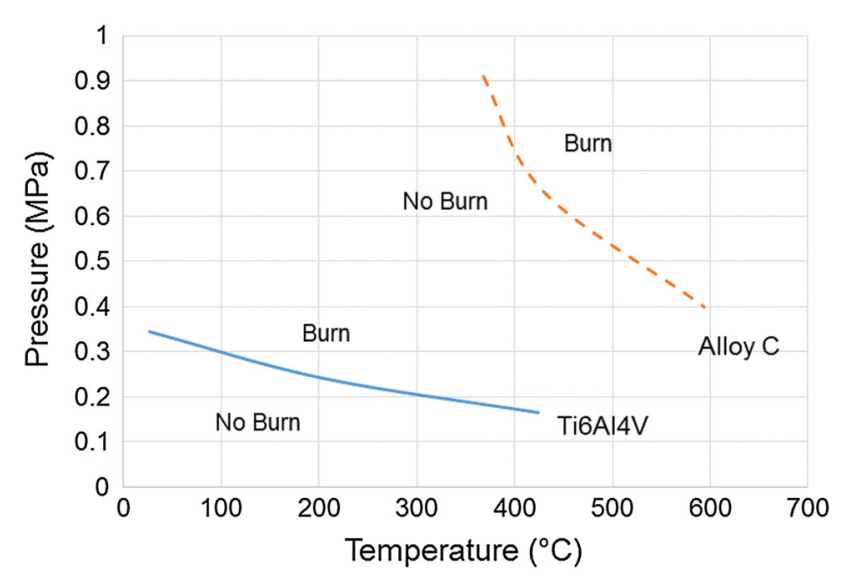

Fig. 25. Comparative burn resistance of alloy and Ti6Al4V. ${ }^{91}$ Burn resistance was assessed by placing a sample $1.78-\mathrm{mm}$-thick sheet having a knife edge into an air stream flowing at $137 \mathrm{~m} / \mathrm{s}$ and attempting to ignite the sample using a $200 \mathrm{~W} \mathrm{CO}_{2}$ laser impinging directly on the knife edge of the sample. These test conditions simulate those encountered in turbine engine operating conditions. ${ }^{92}$

pressure-temperature diagram ${ }^{98}$ and illustrates the improved performance of Alloy $\mathrm{C}$ in a flowing hot gas stream. Alloy $\mathrm{C}$ also offers high elevated temperature strength, ${ }^{91}$ although sustained use temperatures are recommended not to exceed $540^{\circ} \mathrm{C} .^{91}$

\section{CHALLENGES TO THE GROWTH OF BETA ALLOYS}

Despite flexible property suites and remarkable performance capabilities, beta titanium alloy usage has not expanded significantly since the 1990 s. The reason for this lack of growth is cost-beta titanium alloys generally contain significant percentages of rather expensive transition elements (Mo, V, and $\mathrm{Cr}$ ), and the formulation costs can be substantially higher than high-volume alloys such as Ti6Al4V. Melt rates often have to be slower to promote ho- 
mogeneity, which increases ingot cost. In contrast, beta titanium alloys generally offer more forgiving downstream processes, which can improve yield (e.g., precision Ti-10-2-3 forgings) and/or production rate (e.g., strip-producible Beta 21S), and should help compensate for higher raw material costs. Also, the improved performance they offer should bring a greater value and offset higher component costs. So what is impeding further growth? This question was partially addressed 20 years ago by Eylon et al., ${ }^{6}$ with the following points:

1. Higher formulation costs compared with conventional alpha/beta alloys.

2. More complex processing and narrower process windows.

3. Higher density than competing alpha/beta alloys, resulting in heavier components in minimum gauge designs.

4. Microstructural thermal instability, which becomes more significant when processing parts of varying cross section or large size.

5. Higher machining costs.

6. Lack of sufficient design data.

These reasons remain valid. One might also add the following to the list:

7. Low production volumes-If production volumes are too low, then it becomes difficult to justify a single heat of material on a sporadic basis, and the risk of something going wrong will add a proportionate amount of cost. Because beta titanium alloys are only $1-3 \%$ of overall titanium production volumes, they are disruptive to the shop floor and procedures.

8. Property scatter-This was discussed by Rosenberg, ${ }^{45}$ who noted that minor variations in chemistry, cooling rate, heating rate and prior thermomechanical history can all affect the aging response of beta alloys. Melt practice is the primary source of chemistry variation, although subsequent thermal practice can help mitigate. Large components, such as aircraft landing gear, will exhibit the most obvious variations in these parameters. The resulting scatter in properties can produce a correspondingly low statistical design value to ensure that all regions of the forging meet minimums. Rosenberg suggested that the most important source of scatter was differences in aging kinetics, and that the processing rules to minimize such scatter are to (I) fully recrystallize and (II) overage using the highest possible aging temperature that will produce the desired properties. The reason has to do with the fact that the rising part of the aging curve is the most sensitive to nucleation rate. Also, end users should use the longest aging cycles possible to move away from this most variable stage and take advantage of the stability of longer cycles. The down side to this approach is that long aging cycles require more furnace time and are thereby more expensive; this has led to a standard aging time of about $8 \mathrm{~h}$, which is a good compromise.

9. Diminished opportunity space-Perhaps the primary reason for difficulty in the introduction of new beta titanium alloys is that the opportunity space was addressed between the 1970s and the 1990s. The six production beta alloys described above have Mo-Eq values of: 9.5 (Ti10-2-3), 9.6 (Ti5553), 11.9 (Ti-15V-3Al-3Sn-3Cr), 12.8 (Beta 21S), 16.0 (Beta C), and 47.5 (Alloy C), which covers the heat treatable range of 10-16 fairly well and offers the one (essentially) stable beta alloy, Alloy C. Because reasonably reliable alloys are now available to cover the majority of market applications (Ti-10-2-3 and Ti5553 for forgings, Ti-15V-3Al-3Sn-3Cr for strip, Beta C for springs and fasteners), the niche was filled adequately and is difficult to displace. Each new material requires millions of dollars to develop, mature, and qualify. There's inadequate reason to develop new alloys on the basis of incremental performance relative to known alloys unless there is a performance niche that is missing (e.g., Beta 21S for hot hydraulic fluid corrosion resistance, or Alloy $\mathrm{C}$ for burn resistance) or unless there is a clear cost reduction opportunity as yet undiscovered.

10. Flaw sensitivity-Several beta alloys have shown the potential to achieve remarkably high strengths, above $1379 \mathrm{MPa}$ (200 ksi). However, high-strength alloys, irrespective of alloy system, have reduced tolerance for flaws, according to the Griffith criterion, and hence a greater sensitivity to chemical, microstructural, manufacturing, and service discontinuities. This is why very high-strength alloys and conditions are generally confined to small-volume applications, such as fasteners and springs, where variability is constrained and inspection easier.

11. Cost as a primary driver-In the present competitive aerospace market, component cost outranks performance as a reason for adoption.

The challenges noted in the preceding list might explain why the introduction of excellent offerings, such as Beta LCB, Beta III, and Beta CEZ have had difficulty displacing longstanding beta alloys or finding new applications. Beta LCB, in particular, held a great deal of promise as a low-cost solution, as much as half the cost of Beta $\mathrm{C}$ but with little success. ${ }^{17}$ However, these challenges can also provide guidance for future development. For example, new beta titanium systems need to be discovered and developed with the following characteristics:

1. Minimal propensity for ingot segregation

2. Highly robust chemistry and processing windows-incorporating easy alpha nucleation schemes and deep hardenability without rapid quench rates 
3. Innately refined grain structures (e.g., by boronmodification)

4. Alternative precipitating phases to hcp alpha

5. Improved machinability without unacceptable property degradation

6. Improved resistance to interstitial accumulation and embrittlement at elevated temperatures

7. Inherently good galling and wear resistance

It is anticipated that maturing computational methods incorporating thermodynamic and kinetic modeling of microstructure development will refine and supersede the well-established beta titanium alloys and identify innovative new solutions to structural design challenges, and that the above suggestions are useful. To be successful, alloy suppliers and developers must always consider the full range of potential end use requirements, in particular, the impacts of chemistry and processing choices on final component cost. Peripheral aspects, such as toxicity, recyclability, and quality, often drive material choices as much as performance and cost.

\section{SUMMARY}

Beta titanium alloys fill an important role in the aerospace industry. Although only a small fraction of overall titanium production, they maintain a performance niche where high specific strength, corrosion resistance, and good formability are required that cannot be easily satisfied by other materials. Currently, six beta titanium alloys are known to be in steady production: Ti-10V-2Fe-3Al, Ti-15V-3Cr-3Sn-3Al, Ti-3Al-8V-6Cr-4Zr-4Mo (Beta C), Ti-15Mo-2.7Nb-3Al-0.2Si (Beta 21S), Ti5Al5V5Mo3Cr0.5Fe, and Ti-35V-15Cr (Alloy C). Most of these alloys develop properties by a solution treat and age heat-treatment in which alpha precipitates as the hardening phase in a beta matrix. In some cases, nucleation of alpha depends on precursor phases, such as omega or $\beta^{\prime}$; in other cases, precipitation of metastable phases must be avoided. In the more highly stabilized beta alloys, the degree of prior cold work influences aging kinetics, and hence are sensitive to the degree of local work. Across the board, a solid understanding of the complex metallurgy behind this alloy classes is requisite for their use.

Despite progressive alloy development, it has been difficult to displace these well-established performers, several of which have been in production since their introduction in the 1970s. In a sense, important niches have been filled. Growth of new beta titanium alloys and applications will require advances in end-item cost reduction, robustness, or functionality that significantly exceeds currently available materials.

\section{REFERENCES}

1. T.W. Duerig and J.C. Williams, Beta Titanium Alloys in the 1980s, Proceedings of the Symposium at Annual Meeting of
The Metallurgical Society of AIME, eds. R.R. Boyer and H.W. Rosenberg (New York: American Institute of Mining, Metallurgical and Petroleum Engineers, 1984), pp. 19-67.

2. F.H. Froes and H.B. Bomberger, JOM 37, 28 (1985).

3. R.R. Boyer, JOM 44, 23 (1992).

4. P.J. Bania, JOM 46, 16 (1994).

5. D. Eylon (Paper presented at the Proceedings of the International Workshop on Beta Titanium Alloys, Paris, France, 1994), pp. 75-82.

6. D. Eylon, A. Vassel, Y. Combres, R.R. Boyer, P.J. Bania, and R.W. Schutz, JOM, pp. 14-15 (1994).

7. S.K. Jha and K.S. Ravichandran, JOM 52, 30 (2000).

8. R.R. Boyer and R.D. Briggs, JMEPEG 22, 2916 (2013).

9. S.L. Nyakana, J.C. Fanning, and R.R. Boyer, JMEPEG 14, 799 (2005).

10. G. Lutjering and J.C. Williams, Titanium, 2nd ed. (Berlin, Germany: Springer-Verlag, 2007), pp. 283-336.

11. E.W. Collings, The Physical Metallurgy of Titanium Alloys, 1st ed. (Metals Park, OH: American Society for Metals, 1984).

12. E.K. Molchanova, Phase Diagrams of Titanium Alloys, Israel Program for Scientific Translations, 1965, pp. 153-158.

13. J.L. Murray, Phase Diagrams of Binary Titanium Alloys, Monograph Series on Alloy Phase Diagrams (Metals Park, OH: ASM International, 1987), pp. 68, 99.

14. R.I. Jaffee, JOM 7, 247 (1955).

15. J.C. Williams, private communication, 2015.

16. H.W. Rosenberg, The Science, Technology and Application of Titanium, Proceedings. 1st International Conference on Titanium, eds. R.I. Jaffee and N.E. Promisel (Oxford, U.K.: Pergamon Press, 1970), pp. 851-859.

17. R.R. Boyer, JOM 46, 20 (1994).

18. P.D. Frost, R.A. Wood, and R.I. Jaffee, JOM 15(2), 141 (1963).

19. R.R. Boyer and H.W. Rosenberg, Beta Titanium Alloys in the 1980s, Proceedings of the Symposium at Annual Meeting of The Metallurgical Society of AIME, eds. R.R. Boyer and H.W. Rosenberg (New York: American Institute of Mining, Metallurgical and Petroleum Engineers, 1984), pp. $1-8$.

20. D.E. Thomas, S. Ankem, W.D. Goodin, and S.R. Seagle, Industrial Applications of Titanium and Zirconium, vol. 4, ASTM STP 917, eds. C.S. Young and J.C. Durham (Philadelphia, PA: American Society for Testing and Materials, 1984), pp. 144-163.

21. P.J. Bania and W.M. Parris, Titanium Prod. Appl., Proc. Tech. Program Int. Conf., vol. 2 (1990), pp. 784-793.

22. J.S. Graumann, Beta Titanium Alloys in the 1990s, eds. D. Eylon, R.R. Boyer, and D.A. Koss (Pittsburgh, PA: The Minerals, Metals \& Materials Society, 1993), pp. 127-135.

23. D.U. Furrer, United Technologies Corp., personal communication, East Hartford, CT, 2015.

24. V.V. Tetyukhin (Paper presented at the Proc. 13th Annual Titanium Conference, San Francisco, CA, 1997), pp. 37-54.

25. V.V. Tetyukhin, J.I. Zakharov, and I.V. Levin, U.S. patent US7,332,043 (23 January 2002).

26. L. Fleming, Titanium Prod. Appl., Proc. Tech. Program Int. Conf., vol. 2, (1990), pp. 54-61.

27. R.R. Boyer, G. Welsch, and E.W. Collings, eds., Materials Properties Handbook: Titanium Alloys (Materials Park (OH: ASM International, 1994), pp. 797-827.

28. F.H. Froes, ed., TITANIUM: Physical Metallurgy, Processing and Applications (Materials Park, OH: ASM International, 2015), p. 133.

29. M.J. Donachie, Titanium: A Technical Guide, 2nd ed. (ASM International: Materials Park, OH, 2000).

30. G. Lutjering and J.C. Williams, Titanium, 2nd ed. (Berlin, Germany: Springer-Verlag, 2007), pp. 38-42.

31. Y. Koskaka, S.P. Fox, K. Faller, and S.H. Reichman, JMEPEG 14, 792 (2005).

32. C.T. Olofson and F.W. Boulger, Memorandum 121, Defense Metals Information Center (DMIC), Battelle Memorial Institute, Columbus, OH, 3 Aug 1961.

33. C.C. Chen and R.R. Boyer, JOM 31, 33 (1979). 
34. R.R. Boyer and G.W. Kuhlman, Metall. Trans. A 18A, 2095 (1987).

35. P. Auburtin, C. Edie, B. Foster, I. Mackenzie, A. Mitchell, and A. Schmalz (Paper presented at the Proceedings of the 1997 International Symposium on Liquid Metal Processing and Casting, Santa Fe, NM, 1997), pp. 60-77.

36. A. Mitchell, JOM, 40 (1997).

37. K.O. Yu, M.P. Jacques, and S.R. Giangiordano (Paper presented at Titanium 2011 ITA Annual Meeting, October 2011).

38. G.W. Kuhlman, R. Pishko, J.R. Kahrs, and J.W. Nelson, Proceedings of the Symposium at Annual Meeting of The Metallurgical Society of AIME (New York: American Institute of Mining, Metallurgical and Petroleum Engineers, 1984), pp. 255-280.

39. R.R. Boyer and H.W. Rosenberg, Beta Titanium Alloys in the 1980s, Proceedings of the symposium at Annual Meeting of The Metallurgical Society of AIME, eds. R.R. Boyer and H.W. Rosenberg (New York: American Institute of Mining, Metallurgical and Petroleum Engineers, 1984), pp. 441-456.

40. I. Weiss and S.L. Semiatin, Mater. Sci. Eng. A 243, 46 (1998).

41. F.H. Froes, J.C. Chesnutt, C.G. Rhodes, and J.C. Williams, Toughness and Fracture Behavior or Titanium, ASTM STP 651 (Baltimore, MD: ASTM, 1978), p. 111.

42. R.D. Briggs, U.S. patent 2004/0250932 A1 (16 December 2004).

43. S. Ankem and S.R. Seagle, Proceedings of the Symposium at Annual Meeting of The Metallurgical Society of AIME, eds. R.R. Boyer and H.W. Rosenberg (New York: American Institute of Mining, Metallurgical and Petroleum Engineers, 1984), pp. 107-128.

44. T.W. Duerig, J.E. Allison, and J.C. Williams, Metall. Trans. A 16A, 739 (1985).

45. H.W. Rosenberg, Proceedings of the Symposium at Annual Meeting of The Metallurgical Society of AIME, eds. R.R. Boyer and H.W. Rosenberg (New York: American Institute of Mining, Metallurgical and Petroleum Engineers, 1984), pp. $145-160$.

46. G. Terlinde, H.-J. Rathjen, and K.-H. Schwalbe, Metall. Trans. A 19A, 1037 (1988).

47. J.C. Fanning, JMEPEG 14, 788 (2005).

48. J.C. Fanning, Beta Titanium Alloys in the 1990 s, Proceedings Symposium of The Metallurgical Society of AIME, eds. D. Eylon, R.R. Boyer, and D.A. Koss (New York: The Minerals, Metals \& Materials Society, 1993), pp. 397-410.

49. J.C. Fanning and S.P. Fox, JMEPEG 14, 703 (2005).

50. J. Jackson and R. Rice, Preliminary Material Properties Handbook, vol. 1: English Units (Columbus, OH: Battelle Memorial Institute, 2000).

51. H.-J. Christ, M. Decker, and S. Zeitler, Metall. Mater. Trans. A 31A, 1507 (2000).

52. ISO 642:1999, Steel-Hardenability test by end quenching (Jominy test).

53. J.R. Toran and R.R. Biederman, Titanium '80 (Warrendale, PA: TMS, 1980), pp. 1491-1501.

54. T.J. Headley and H.J. Rack, Metall. Trans. A 10A, 909 (1979).

55. S. Malinov, W. Sha, and P. Markovksy, J. Alloys. Compd. 348, 110 (2003).

56. J.D. Cotton, R.R. Boyer, R.D. Briggs, R.G. Baggerly, C.A. Meyer, M.D. Carter, W. Wood, G. Tewksbury, V. Li, and X. Yao (Paper presented at the World Conf. on Titanium, Ti2007 Science and Technology, Kyoto, Japan, 2007), pp. 471474.

57. N. Niwa, T. Demura, and K. Ito, ISIJ Int. 30, 773 (1990).

58. S.K. Kar, A. Ghosh, N. Fulzele, and A. Bhattacharajee, Mater. Charact. 81, 37 (2013).

59. W. Parris and H.W. Rosenberg, U.S. patent US3,802,877 (9 April 1974).

60. G.W. Kuhlman, Beta Titanium Alloys in the 1990s, Proceedings Symposium of The Metallurgical Society of AIME, eds. D. Eylon, R.R. Boyer, and D.A. Koss (New York: The Minerals, Metals \& Materials Society, 1993), pp. 485-512.
61. AMS 4984E, Titanium Alloy Forgings, 10V-2Fe-3Al, Consumable Electrode Melted, Solution Heat Treated and Aged, $173 \mathrm{ksi}(1193 \mathrm{MPa})$ Tensile Strength.

62. AMS 4987E, Titanium Alloy, Forgings 10V-2Fe-3AI Consumable Electrode Melted, Single-Step Solution Heat Treated and Overaged $140 \mathrm{ksi}(965 \mathrm{MPa})$ Tensile Strength.

63. R.R. Boyer, JOM, 61 (1980).

64. J.F. Uginet (Paper presented at the Proceedings International Workshop on Beta Titanium Alloys, Paris, France, 1994), pp. 33-40.

65. AMS 4983F, Titanium Alloy, Forgings, 10V-2Fe-3Al, Consumable Electrode Melted, Single-Step Solution Heat Treated and Aged, $180 \mathrm{ksi}$ (1241 MPa) Tensile Strength.

66. AMS 4986E, Titanium Alloy, Forgings 10V-2Fe-3Al Consumable Electrode Melted, Single-Step Solution Heat Treated and Overaged $160 \mathrm{ksi}$ (1103 MPa) Tensile Strength.

67. T.W. Duerig, G.T. Terlinde, and J.C. Williams, Metall. Trans. A 11A, 1987 (1980).

68. G.T. Terlinde, T.W. Duerig, and J.C. Williams, Metall. Trans. A 14A, 2101 (1983).

69. H.W. Rosenberg, JOM, 30 (1983).

70. T.L. Wardlaw, H.W. Rosenberg, and W.M. Parris, Titanium Metals Corporation of America, Henderson, NV, Defense Technical Information Center, 1972.

71. M.E. Rosenblum, A. Shames, and W.B. Treppel, Beta Titanium Alloys in the 1980s, Proceedings of the Symposium at Annual Meeting of The Metallurgical Society of AIME, eds. R.R. Boyer and H.W. Rosenberg (New York: American Institute of Mining, Metallurgical and Petroleum Engineers, 1984), pp. 307-329.

72. AMS 4914F, Titanium Alloy Cold Rolled Sheet and Strip, 15V-3Al-3Cr-3Sn, Solution Heat Treated.

73. T. Furuhara, T. Maki, and T. Makino, J. Mater. Proc. Tech. 117,318 (2001).

74. T. Makino, R. Chikaizumi, T. Hagaoka, T. Furuhara, and T. Makino, Mater. Sci. Eng. A 213, 51 (1996).

75. J. Del Prado, X. Song, D. Hu, and X. Wu, JMEPEG 14, 728 (2005).

76. K.O. Yu, E.M. Crist, R. Pesa, N. Cecchini, and C.M. Bugle, JMEPEG 14, 697 (2005).

77. AMS 4957E, Titanium Alloy, Round Bar and Wire, 3AI-8V6Cr-4Mo-4Zr, Consumable Electrode Melted, Solution Heat Treated and Cold Drawn.

78. C.G. Rhodes and N.E. Paton, Metall. Trans. A 8A, 1749 (1977).

79. G. Polek, "More details on 737 Max materials emerge," Aviation International News, 3 June 2013, http://www.ai nonline.com/aviation-news/air-transport/2013-06-03/moredetails-737-max-materials-emerge.

80. AMS 4897C, Titanium Alloy, Sheet and Strip, 15Mo-3.0Al$2.8 \mathrm{Cb}-0.20 \mathrm{Si}$.

81. F. Sanzoz, M. Almesallmy, and H. Ghonem, Metall. Trans. A 35A, 3113 (2004).

82. O.M. lvasishin, P.E. Markovsky, R.V. Teliovich, and Y.V. Matviychuk, Key Eng. Mater. 188, 63 (2000).

83. K. Chaudhuri and J.H. Perepezko, Metall. Trans. A 25A, 1109 (1994).

84. M.A. Imam and C.R. Feng, Titanium'95, Science and Technology (Cambridge, U.K.: The University Press, 1996), p. 2361.

85. R. Luthra, J. Park, M. Standish, and M. Lakhavani, Development and Construction of Time Temperature Transformation Diagram for Titanium Beta-21S Alloy, MSE Capstone Project \#27-401 (4 December 2013).

86. G. Tomchik, "Overview of Titanium Applications on Advanced Commercial Transports," AeroMat Conference, unpublished research, 15 May 2006.

87. J. Pora, Flight Airworth. Support Tech. 32, 3 (2003).

88. N.G. Jones, R.J. Dashwood, D. Dye, and M. Jackson, Mater. Sci. Eng. A 490, 369 (2008).

89. S. Nag, Y. Zheng, R.E.A. Williams, A. Devaraj, A. Boyne, Y. Wang, P.C. Collins, G.B. Viswanathan, J.S. Tiley, B.C. Muddle, R. Banerjee, and H.L. Fraser, Acta Mater. 60, 6247 (2012). 
90. D.W. Anderson and A.F. Condliff (Paper presented at the proceedings of International Titanium Associations, TITANIUM 1994, Products and Applications), pp. 191-201.

91. "TWCA to Commercially Market Alloy C," Teledyne Wah Chang Albany, OUTLOOK Newsletter, 14(1), 1 (1993).

92. D.M. Berczik, U.S. patent US5,176,762 (5 January 1993).

93. R.W. Schutz, JOM 46, 24 (1994).

94. G. Li, D. Li, Y. Liu, Q. Wang, and S. Guan, J. Mater. Sci. Tech. 14, 411 (1998).

95. X.-X. Wang, W.-Q. Wang, and Y.-Q. Zhang, Mater. Sci. Forum 765, 506 (2013).
96. Y.G. Li, M.H. Loretto, D. Rugg, and W. Voice, Acta Mater. 49, 3011 (2001).

97. Z. Yongqing, Z. Lian, Z. Kangying, Q. Henglei, and W. Huan, Int. J. Mater. Prod. Tech. 604 (2001).

98. G. Lutjering and J.C. Williams, Titanium, 2nd ed. (Berlin, Germany: Springer-Verlag, 2007), pp. 390-391.

99. C.C. Wojcik, European patent 0413496 A1 (20 February 1991). 100. B.K. Damkroger, G.A. Knorovsky, T.J. Headley, J.R. Michael, and J.O. Hansen (Paper presented at the International Welding Exposition and Annual Conference, Philadelphia, PA, 10-14 April 1994). 